\title{
Direct dating of overprinting fluid systems in the Martabe epithermal gold deposit using highly retentive alunite
}

\author{
Jack Muston ${ }^{1}$, Marnie Forster ${ }^{2}$, Davood Vasegh ${ }^{2}$, Conrad Alderton $^{3}$, Shawn Crispin ${ }^{3}$, Gordon Lister ${ }^{4}$ \\ ${ }^{1}$ AngloGoldAshanti, Perth, 2601 Australia \\ $5 \quad{ }^{2}$ Structure Tectonics Team, Research School of Earth Sciences, Australian National University, Canberra, 2601 Australia \\ ${ }^{3}$ PT Agincourt Resources, Martabe Mine, Sumatra, Indonesia \\ ${ }^{4}$ Sustainable Minerals Institute, WH Bryan Mining and Geology Research Centre, The University of Queensland, Brisbane \\ 4068, Australia
}

Correspondence to: Gordon Lister (director@thevirtualexplorer.com.au)

10 Abstract. The Martabe deposits in Sumatra, Indonesia formed in a shallow crustal epithermal environment $\left(200-350^{\circ} \mathrm{C}\right)$ associated with mafic intrusions, usually recognised in domes, adjacent to an active right-lateral wrench system. Ten samples containing alunite were collected for high-resolution geochronology, to determine if overprinting fluid systems could be recognised by dating alunite separates. The heating time for each step was chosen to ensure reasonable uniformity in terms of the incremental percentage of ${ }^{39} \mathrm{Ar}$ gas release during each of many steps, allowing age spectra to be analysed using the method of asymptotes and limits. Several distinct growth events could be recognised. In addition, each sample was subjected to ultra-high-vacuum (UHV) furnace step-heating, and ${ }^{39} \mathrm{Ar}$ diffusion experiments conducted at the same time as ${ }^{40} \mathrm{Ar} /{ }^{39} \mathrm{Ar}$ geochronology, to determine the argon retentivity of the mineral grains being analysed. The heating schedule ensured Arrhenius data uniformly populated the inverse temperature axis, with sufficient detail to allow the application of the Fundamental Asymmetry Principle (FAP) during analysis of the Arrhenius spectrum. Results show activation energies between $370-660 \mathrm{~kJ} / \mathrm{mol}$. Application of Dodson's recursion determines that closure temperatures would range from $400-560^{\circ} \mathrm{C}$ for a cooling rate of $20^{\circ} \mathrm{C} / \mathrm{Ma}$, which is higher than any possible temperature to be expected in the natural system. This gives confidence that the ages

25 represent growth during periods of active fluid movement and alteration, since the deposit formed at temperatures $<200^{\circ} \mathrm{C}$ at a depth of $<2 \mathrm{~km}$. We conclude that gold in the Purnama pit was the result of fluid rock interactions during very short-lived mineral growth episodes at $\sim 2.25$ and $\sim 2.00 \mathrm{Ma}$.

\section{Introduction}

Sumatra has a number of Neogene epithermal deposits of varying size and grade. The southern extent of

30 the island has a number of low-sulphidation epithermal deposits (e.g., Mangani mine, Lebong district), while the north has predominately high-sulphidation epithermal deposits (e.g., Martabe mine, Meluak deposit, and Miwah mine). Over the last decade Sumatra gold production has seen a significant increase, largely due to the successful development of the Martabe gold mine, which began production in 2012. The Martabe gold system was first discovered in 1997 after a positive result from geochemical

surveys conducted on stream sediment within an exploration tenement. This was soon followed by field 
mapping, rock-chip sampling, and aeromagnetic surveying, which led to the discovery of five deposits within a $7 \mathrm{~km}$ by $3 \mathrm{~km}$ corridor.

The largest of these deposits is Purnama, with a resource estimate of 4.3 million ounces of gold and 53 million ounces of silver (open file report Agincourt Resources, 2018). The host rock is a series of

Tertiary mafic flow domes complexes and maar-diatreme breccias. There is a conjugated set of northeast extensional faults that are known to structurally control the fluid pathways for alteration and mineralisation within the Martabe district. These faults splay from the Sumatran Fault System, which is a $1600 \mathrm{~km}$ long wrench system that runs the entire length of Sumatra (Levet et al., 2003). This rightlateral wrench system formed in response to the oblique subduction of the Indo-Australian plate (Barber and Crow, 2005). Continual movement (in conjunction with active volcanism) has provided fluid pathways, localising and enriching the deposits. We set out to explore the spatial and temporal evolution of this fluid system using ${ }^{40} \mathrm{Ar} /{ }^{39} \mathrm{Ar}$ geochronology. Distinction of different fluid systems is essential for using geochemical data to enable vectoring within the resultant alteration systems.

Epithermal gold \pm copper \pm silver deposits form in shallow crustal environments (1-2 km depth). Low-

sulphidation deposits form distal to their source magmas, through mixing and transport by deep groundwater fluids, and are characterised by a reduced sulphur species and $\mathrm{H}_{2} \mathrm{~S}$. In contrast, highsulphidation deposits form from magmatic fluids, proximal to their source intrusion, and are undiluted by groundwaters. In these low-pH conditions, a suite of alteration minerals is formed (e.g., dickite, alunite, kaolin-dickite, pyrophyllite). The mineral alunite $\left[\mathrm{KAl}_{2}\left(\mathrm{SO}_{4}\right)_{2}(\mathrm{OH})_{6}\right]$ is of particular interest as

55 it is a potassium bearing mineral that has been shown to be a useful ${ }^{40} \mathrm{Ar} /{ }^{39} \mathrm{Ar}$ geochronometer for dating alteration systems (e.g., Arribas et al. 1995, 2011). It commonly forms in porphyry and epithermal gold systems when hot, highly acidic fluids interact with and alter potassium-feldspars. During such acid-sulphate alteration, a subset of advanced argillic alteration is distinguished by the formation of alunite (Rye et al., 1992). We used ${ }^{40} \mathrm{Ar} /{ }^{39} \mathrm{Ar}$ geochronology to date 10 alunite samples.

60 Sample locations are shown in Figure 1, with photographs of the actual samples in Figure 2.

The sample sites were chosen to allow distinction of overprinting fluids within the mineralised corridor. Previous work at Martabe has dated alunite using ${ }^{40} \mathrm{Ar} /{ }^{39} \mathrm{Ar}$ geochronology and concluded that the alteration system was active over a broad time period: between $3.30 \pm 0.2 \mathrm{Ma}$ and $2.00 \pm 0.2 \mathrm{Ma}$ (Sutopo, 2013). However, the Sutopo (2013) geochronology was done on only four samples (two of

65 which were fusion ages). Our study will build on these results, increasing the number of samples analysed to provide a more detailed understanding of the geometry and timing of the alteration systems. 
https://doi.org/10.5194/gchron-2021-25

Preprint. Discussion started: 13 September 2021

(c) Author(s) 2021. CC BY 4.0 License.
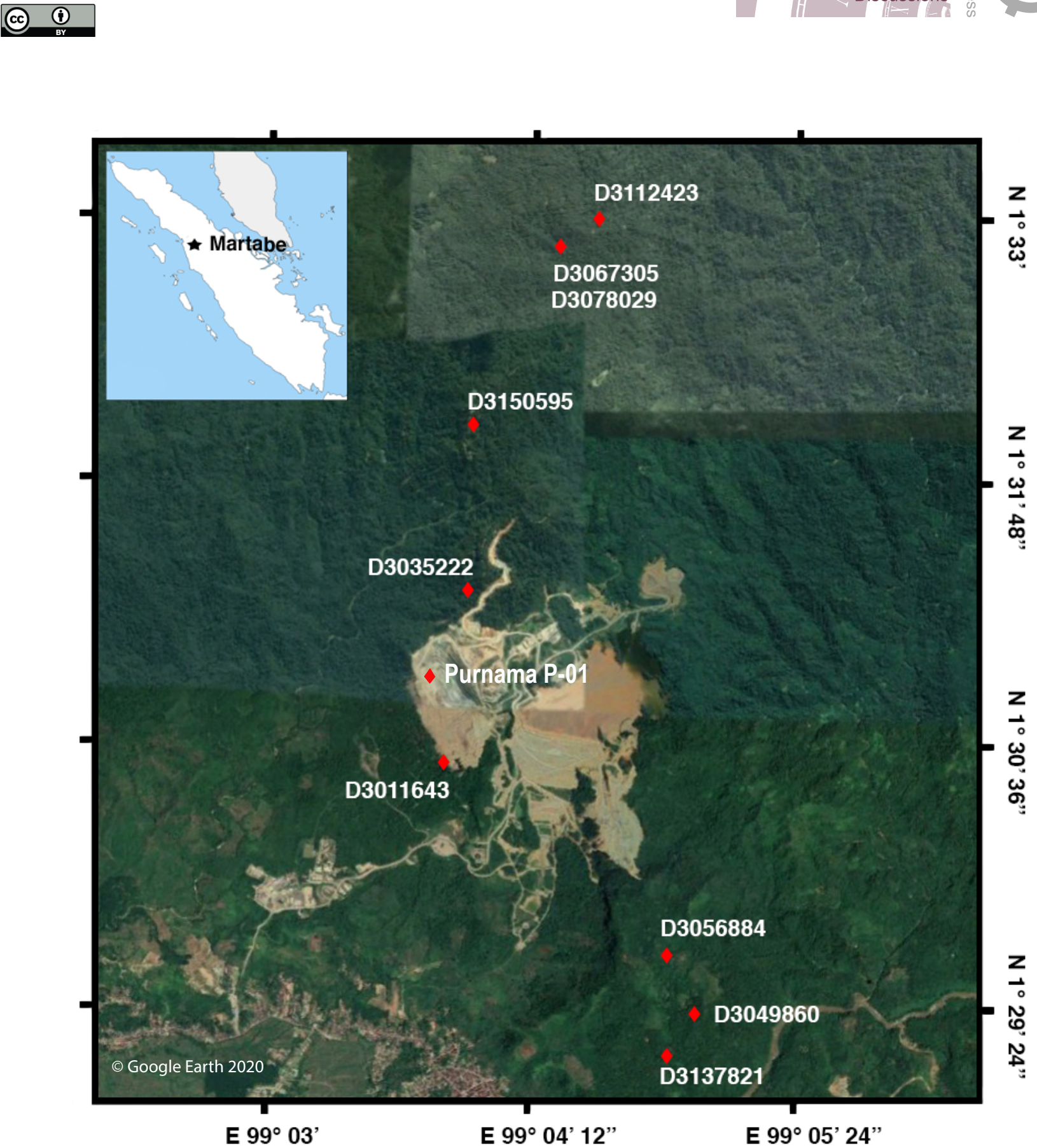

Figure 1. Image of Martabe mine, Sumatra, Indonesia: location of the ten alunite samples shown with red diamonds. Two samples were from the same location. The sample from within the Purnama pit was not precisely located. 

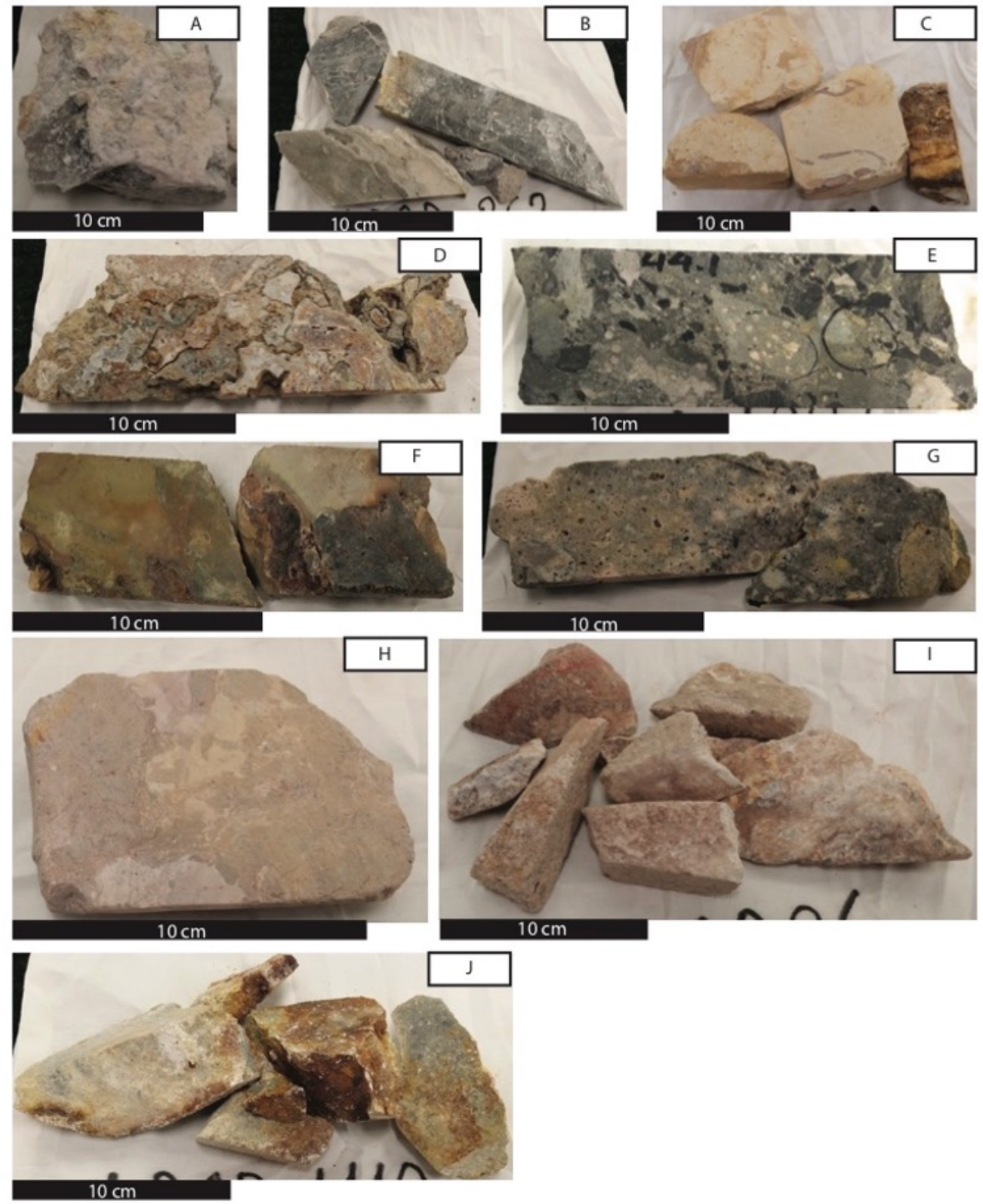

Figure 2. (A) Sample PURNAMA P-01. Fine grained porphyritic volcanic andesite with possible hornblende, pervasive alunite-silica alteration, staining oxide (with disseminated hematite). (B) Sample D3011643. Contact between sediment and quartz vein. (C) Sample D3150595. Fine-grained clay samples with reddish-brown banding, alunite-clay altered. (D) Sample D3112423.

75 Phreatomagmatic breccia, polymict, trace sediment minor clast, altered by alunite-dickite-silica. (E) Sample D3078029. Phreatomagmatic breccia, polymict, trace sediment - minor clast, altered by alunite-dickite-silica (high grade). (F) Sample D3056884. Crackle sandstone, matrix fill by alunite \pm dickite. (G) Sample D3067305. Phreatomagmatic breccia, polymict, altered by alunite-dickite-silica. (H) Sample D3137821. Massive sandstone, oxide staining, pervasive alunite-clay altered. (I) Sample D3035222. Sandstone with alunite vein. (J) Sample D3049860. Phreatomagmatic breccia, altered by alunite-silica, with the alunite matrix partly clast dominant. The purity of alunite separated from these samples was confirmed using XRD analysis. 


\section{Geochronology}

\section{$3.1{ }^{40} \mathrm{Ar} /{ }^{39} \mathrm{Ar}$ Geochronology}

The ${ }^{40} \mathrm{Ar} /{ }^{39} \mathrm{Ar}$ dating technique is described in detail by McDougall and Harrison (1999). The specific methods used here are described by Forster and Lister $(2004,2009,2010,2014)$. New technology of today has enabled the ${ }^{40} \mathrm{Ar} /{ }^{39} \mathrm{Ar}$ geochronometer to become one of the most precise systems available to determine the timing and duration of events that accompany mineralisation. Age is determined based on the amount of ${ }^{40} \mathrm{Ar}$ produced from radioactive decay of ${ }^{40} \mathrm{~K}$, so only potassium bearing rocks or minerals can be analysed using this method. Fortunately, potassium is abundant in a range of geological and tectonic settings. One such mineral is alunite, the mineral that is key to this study. Ten alunite samples (Figure 2) were chosen: the most pristine alunite zones of each sample were cut out. These samples were then crushed to $420-240 \mu \mathrm{m}$ in size and alunite grains were hand-picked and separated under a microscope. The chosen alunite grains have a white-cream colour, soft texture, and anhedral crystal shape with a high (9-10\%) potassium content. Since the ages were estimated to lie between 1 and $3 \mathrm{Ma}, 100-150 \mathrm{mg}$ of alunite per sample were picked with a purity of $99 \%$. XRD verified the purity and mineralogy of the aliquots chosen for analysis.

Data tables are included in the supplementary information. To calibrate the age information recorded by the mass spectrometer a standard of known age must be irradiated and processed under the same conditions during measurement of the samples from the one irradiation canister. This standard has an independently determined age and is used to determine the fast neutron dose that was received for all samples during irradiation. For the experiments in this study the standard GA1550 biotite (98.5 $\pm 0.8 \mathrm{Ma})$ is used (Spell and McDougall, 2003). The reported data have been corrected for system backgrounds, mass discrimination, fluence gradients and atmospheric contamination. Errors associated with the age determinations are two sigma uncertainties, but nevertheless exclude possible errors in the assumed age of the fluence monitor GA1550. Decay constants used are those of Steiger and Jäger (1977).

105 Samples were analysed using a multi-collector ThermoFisher Argus VI at the Australian National University (see information available at URL: http://argon.anu.edu.au/ and in the supplementary information). The samples were step-heated in an ultra-high-vacuum resistance furnace, allowing ${ }^{39} \mathrm{Ar}$ diffusion experiments at the same time as ${ }^{40} \mathrm{Ar} /{ }^{39} \mathrm{Ar}$ geochronology. Each irradiation canister also included salts that allow accurate calibration of the correction factors used to eliminate interference

110 from $\mathrm{Ca}$ and $\mathrm{Cl}$ in producing argon isotopes during the irradiation process. For each step the gas released is measured in the mass spectrometer, producing one ${ }^{40} \mathrm{Ar} /{ }^{39} \mathrm{Ar}$ age measurement, corrected for isotopic interferences from ${ }^{36} \mathrm{Ar}$ and ${ }^{39} \mathrm{Ar}$ (from $\mathrm{Cl}$ and $\mathrm{Ca}$ ) and reactor produced ${ }^{40} \mathrm{Ar}$ (from ${ }^{40} \mathrm{~K}$ ).

The isotopic interferences from ${ }^{36} \mathrm{Ar}$ and ${ }^{39} \mathrm{Ar}$ most likely result from fluid inclusions that contain $\mathrm{KCl}$ and $\mathrm{CaCl}_{2}$ in the form of crystallised salts. Although one can rid a sample of such unwanted inclusions

115 using $\left(\mathrm{HNO}_{3}\right)$ acid, such methods modify the microstructure and may eliminate useful information. Instead, we avoided microstructural damage to the samples by cleaning them in deionised water. To separate the effect of contaminants, we relied on the sequential variation of detail in each of the numerous (32-35) heating steps in the step-heating schedule. Such age spectra have significant detail 
and this is sufficient to overcome any ambiguity caused by contaminated steps. Samples were dropped into the resistance furnace and heated to $400^{\circ} \mathrm{C}$, prior to measurement. The temperature was then immediately reduced, and the sample left for a minimum of 12 hours pumping away unwanted gases. Such long periods of cleaning under UHV conditions prior to measurement minimised the effect of contaminants, especially in the first few steps where low retentivity diffusion domains release their gas. The method utilised allows protracted cleaning of the furnace between samples, so furnace blanks are consistently reduced to low levels. Corrections are done by interpolation, but in general the blanks are so low that this is not essential.

\subsection{Age spectra from resistance-furnace step-heating experiments}

Constraints on timing are critical for understanding regions that have experienced multiple stages of deformation, alteration, and/or magmatism, such as that found at the Martabe gold field. However, age information can be hard to unravel, especially when there were multiple periods of growth associated with alteration. Such samples produce complex apparent age spectra. Forster and Lister (2004) addressed this problem and demonstrated methodology to interpret complex or 'disturbed' age spectra. Hence their method of 'asymptotes and limits' is utilised in this research. In what follows, the steps selected are those that define plateau segments, as well as those that define the asymptotes and limits 135 that characterise the mixing path.

Age spectra consist of the measured age on the y-axis and the percentage of the cumulated percentage total of the ${ }^{39} \mathrm{Ar}$ isotope progressively released during the experiment on the $\mathrm{x}$-axis, calculated retrospectively after the sample has been completely degassed. Disturbed age spectra diverge from a single plateau due to mixing of gas from different microstructural reservoirs, commonly occurring as intra-grain variation, not just from different grains. Using the 'asymptotes and limits' allowed the extraction of relevant age information from the pattern of mixing in the gas released during a single step-heating experiment, including the timing of overprinting growth events.

If a step-heating schedule is chosen so that only small amounts of gas are released in each step, the progression of the variation in the isotopic ratios from one step to the next allows ready identification of different gas populations, as readily shown on a York Plot. The resultant age spectrum allows vastly more information to be ascertained than any laser spot analysis can provide. Furthermore, the strict control of temperature variation with time allows additional analysis, and the production of Arrhenius data. Many small steps with incremental release of ${ }^{39} \mathrm{Ar}$ over a range of different temperatures allows the Arrhenius plot to be uniformly well-populated on the $1 / \mathrm{T}^{\circ} \mathrm{K}$ axis. This is important when estimating argon diffusion parameters and closure temperatures (Forster et al. 2019).

Experience showed that there was variation in how alunite grains degas: alunite samples can degas quickly over a short temperature range. Therefore, we took care in monitoring the heating schedule for our experiments, to prevent large amounts of gas from being released in a single step. If this happens, the resultant spectrum will hide mixing and age variation. Hence, we commenced step-heating at $450^{\circ} \mathrm{C}$ with increments of $20-30^{\circ} \mathrm{C}$ applied until $1000^{\circ} \mathrm{C}$ was reached, with $50^{\circ} \mathrm{C}$ steps thereafter. Figures $3-12$ show age spectra and associated plots from each of these step-heating experiments. 
Figure 3 Data from the Purnama-P01 sample, plotted using the eArgon program: (a) the age spectrum with two distinct plateau segments; (b) the Arrhenius plot, which also shows two distinct diffusion domains, estimated closure temperatures as shown; (c) a comparative radius plot, showing the relative volumes of the two domains; (d) the $\mathrm{Ca} / \mathrm{K}$ ratio inferred from the release of ${ }^{37} \mathrm{Ar}$; (e) the $\mathrm{Cl} / \mathrm{K}$ ratio inferred from the release of ${ }^{38} \mathrm{Ar}$; and (f) the York Plot which shows three inverse isochrons, with only two apparent in the age plot. See text for further detail.
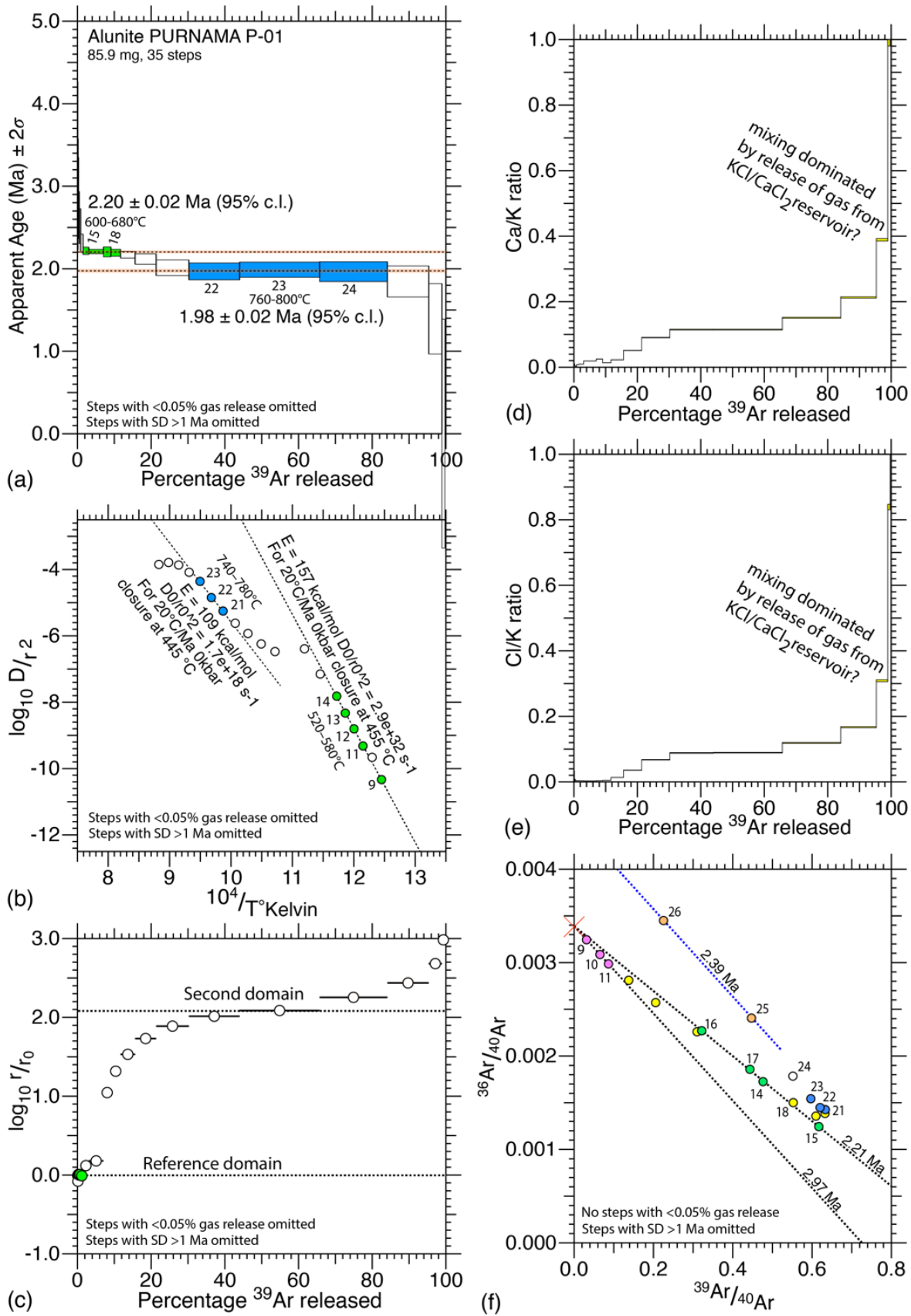
Figure 4 Data from sample D3035222, plotted using the eArgon program: (a) the age spectrum with 165 two distinct plateau segments identified; (b) the Arrhenius Plot, with one distinct diffusion domain, estimated closure temperature as shown; (c) a comparative radius plot, which shows the relative volumes of the two domains; (d) the $\mathrm{Ca} / \mathrm{K}$ ratio inferred from the release of ${ }^{37} \mathrm{Ar}$; (e) the $\mathrm{Cl} / \mathrm{K}$ ratio inferred from the release of ${ }^{38} \mathrm{Ar}$; and (f) the York Plot which shows two inverse isochrons, both consistent with the age plot. See text for further detail.
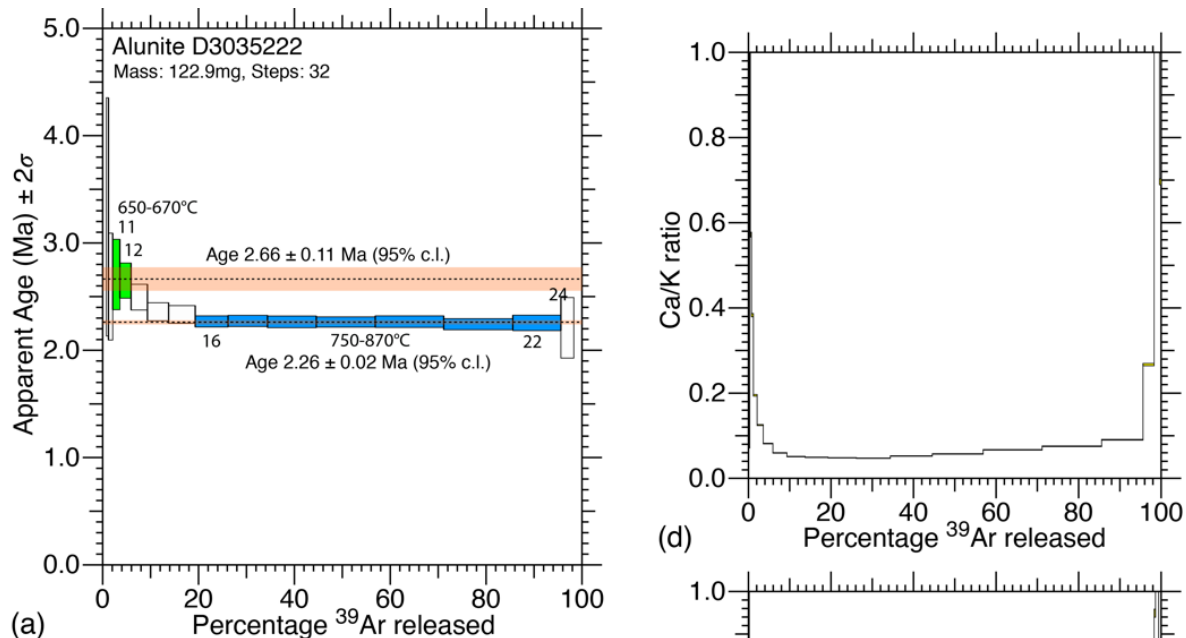

(a)
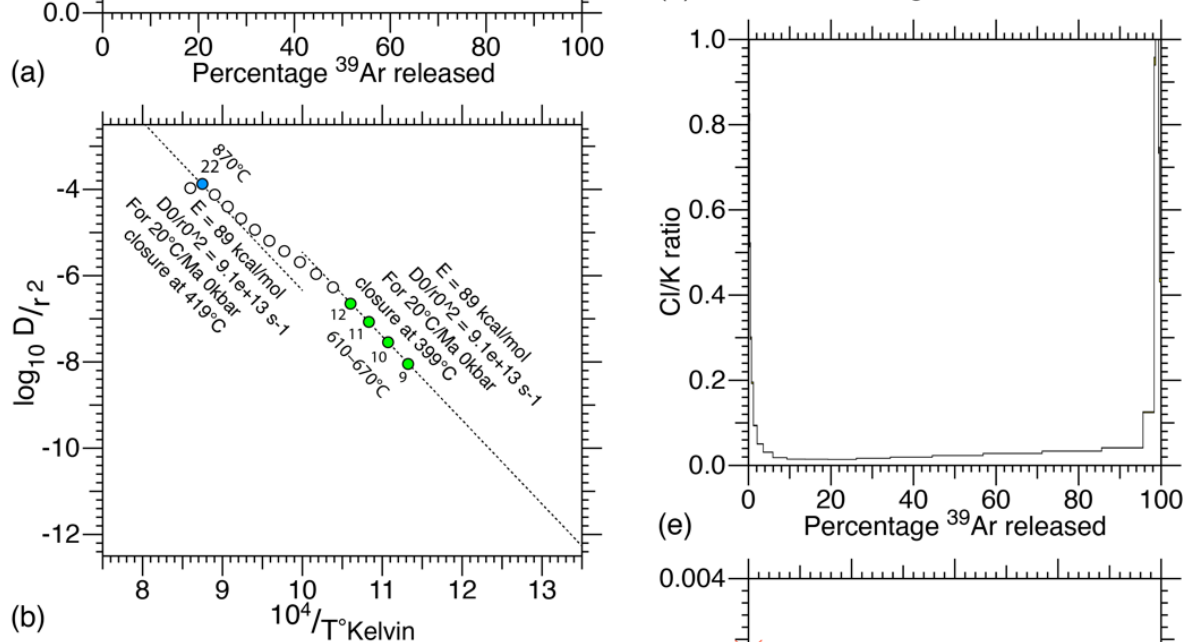

(c)

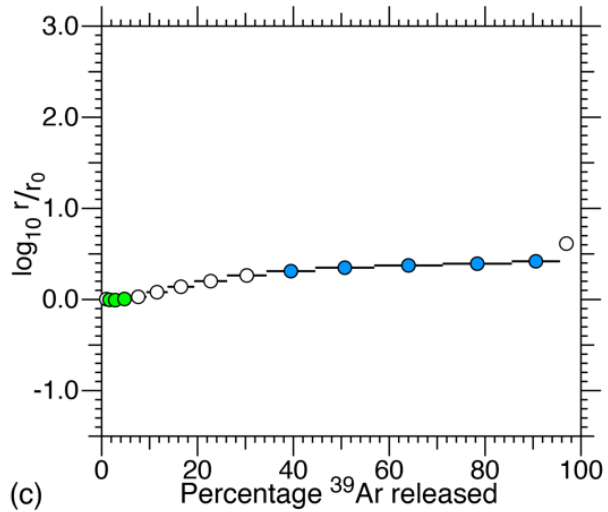

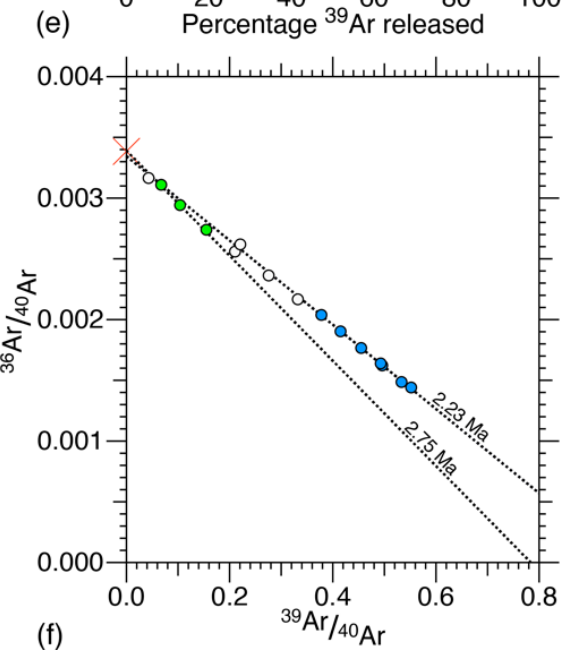

(f) 
Figure 5 Data from sample D3011643, plotted using the eArgon program: (a) the age spectrum has one plateau segment, a lower limit, and then again mixes with domain I; (b) the Arrhenius Plot shows two diffusion domains, which are similar in retentivity, thus explaining the mixing curve; (c) a comparative radius plot, which shows the relative volumes of the two domains; (d) the $\mathrm{Ca} / \mathrm{K}$ ratio inferred from the release of ${ }^{37} \mathrm{Ar}$; (e) the $\mathrm{Cl} / \mathrm{K}$ ratio inferred from the release of ${ }^{38} \mathrm{Ar}$; and (f) the York Plot showing a well-defined inverse isochron for domain I, mixing with domain II, a return to the mixing line for domain I, before looping off towards the $\mathrm{KCl} / \mathrm{CaCl}_{2}$ reservoir. See text for further detail.
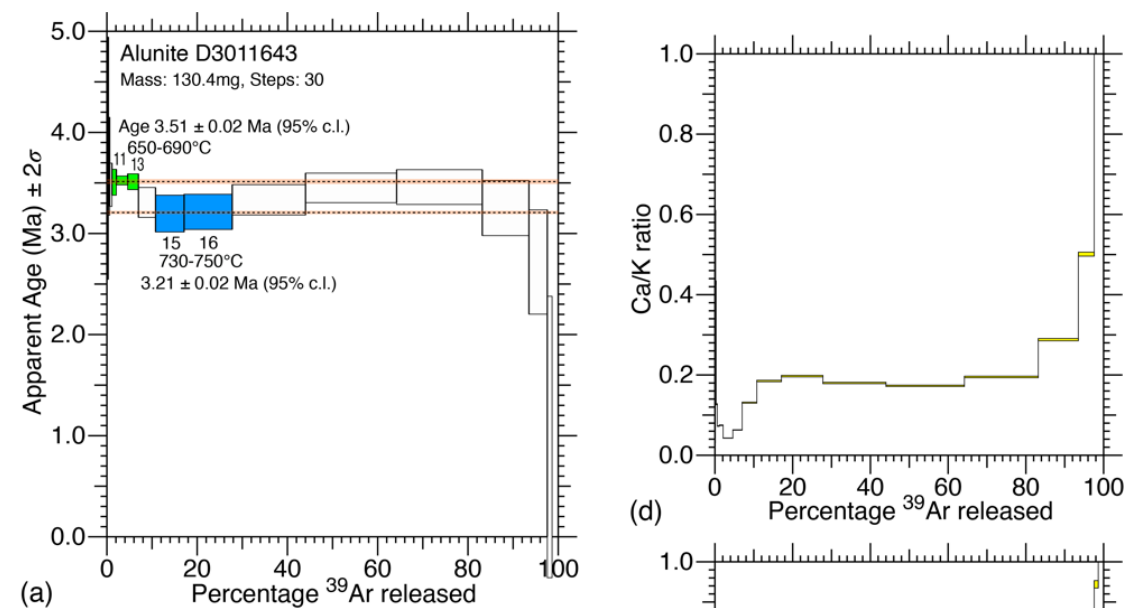

(a)
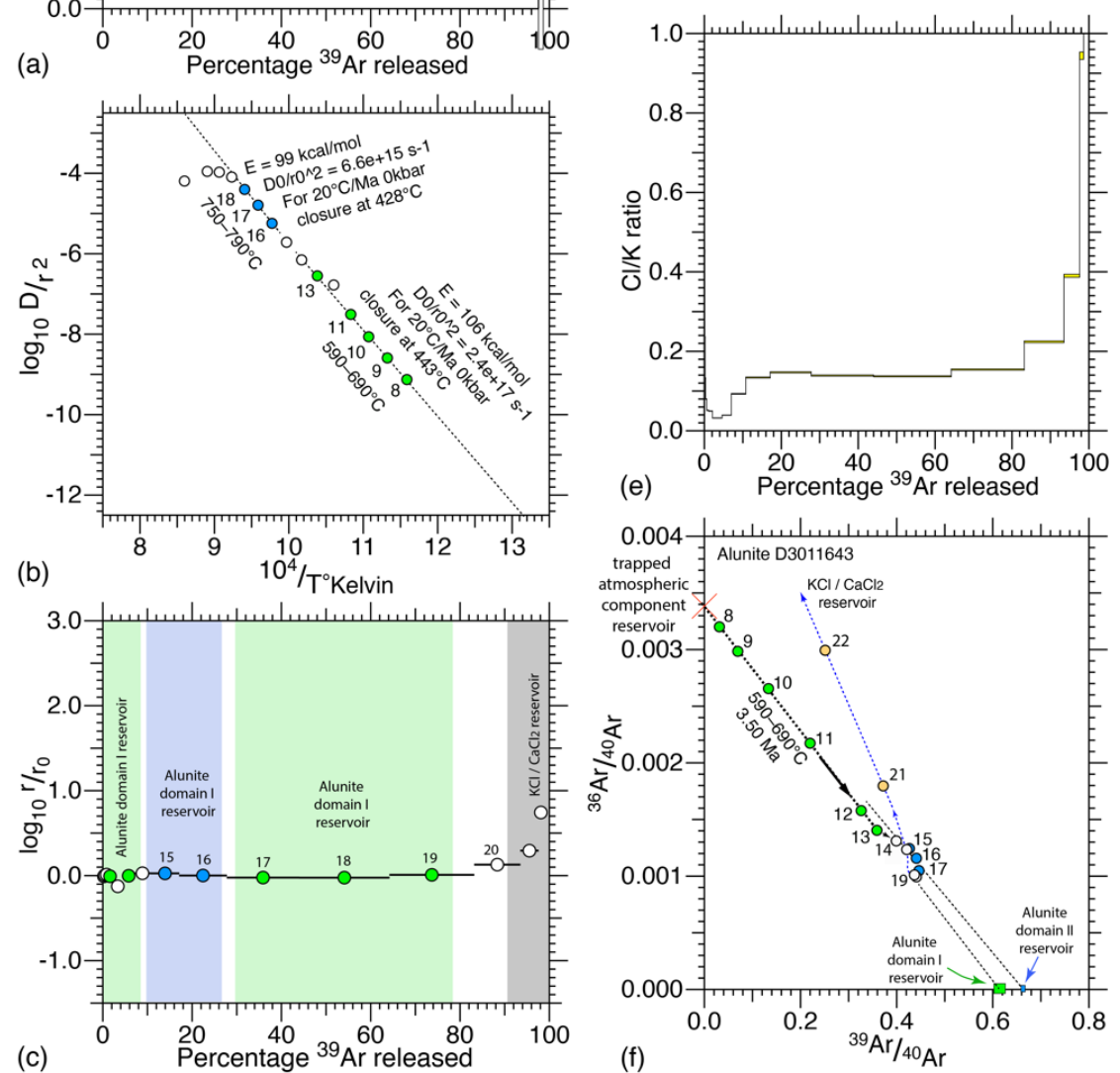

(c)

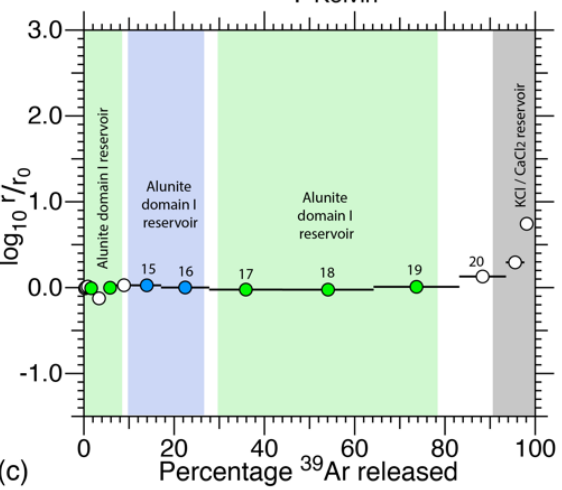

(f) 
180 Figure 6 Data from sample D3112423, plotted using the eArgon program: (a) the age spectrum with upper and lower limits; (b) the Arrhenius Plot, which also shows one estimate of diffusion parameters, estimated closure temperature as shown; (c) a comparative radius plot; (d) the $\mathrm{Ca} / \mathrm{K}$ ratio inferred from the release of ${ }^{37} \mathrm{Ar}$; (e) the $\mathrm{Cl} / \mathrm{K}$ ratio inferred from the release of ${ }^{38} \mathrm{Ar}$; and (f) the York Plot which shows one inverse isochron, for domain I, and the mixing line for domain II. See text for further detail.
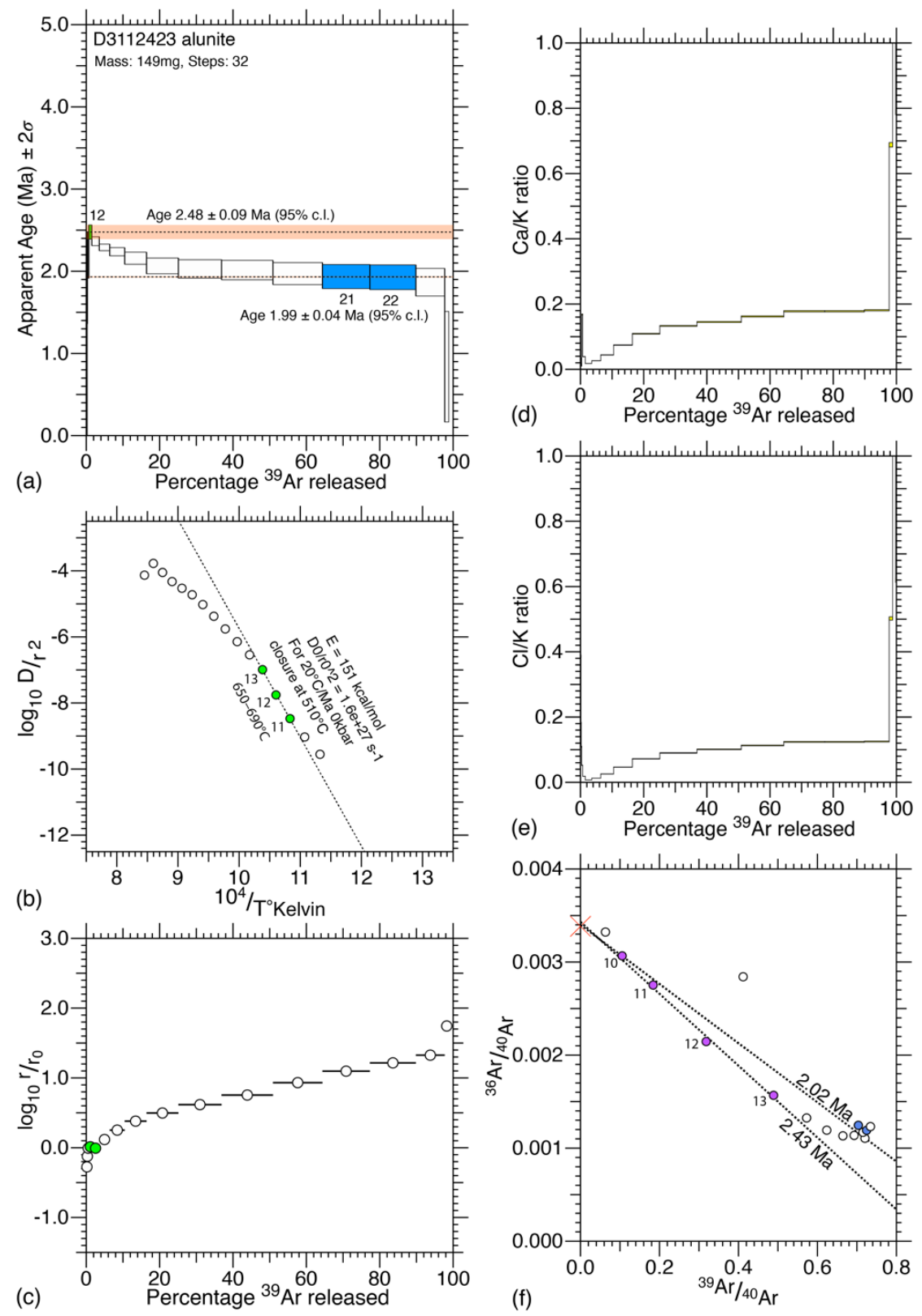
Figure 7 Data from sample D3078029, plotted using the eArgon program: (a) the age spectrum with two small plateau segments; (b) the Arrhenius Plot, with only one distinct diffusion domain, estimated closure temperature as shown; (c) a comparative radius plot; (d) the $\mathrm{Ca} / \mathrm{K}$ ratio inferred from the release of ${ }^{37} \mathrm{Ar}$; (e) the $\mathrm{Cl} / \mathrm{K}$ ratio inferred from the release of ${ }^{38} \mathrm{Ar}$; and (f) the York Plot which shows two inverse isochrons. See text for further detail.
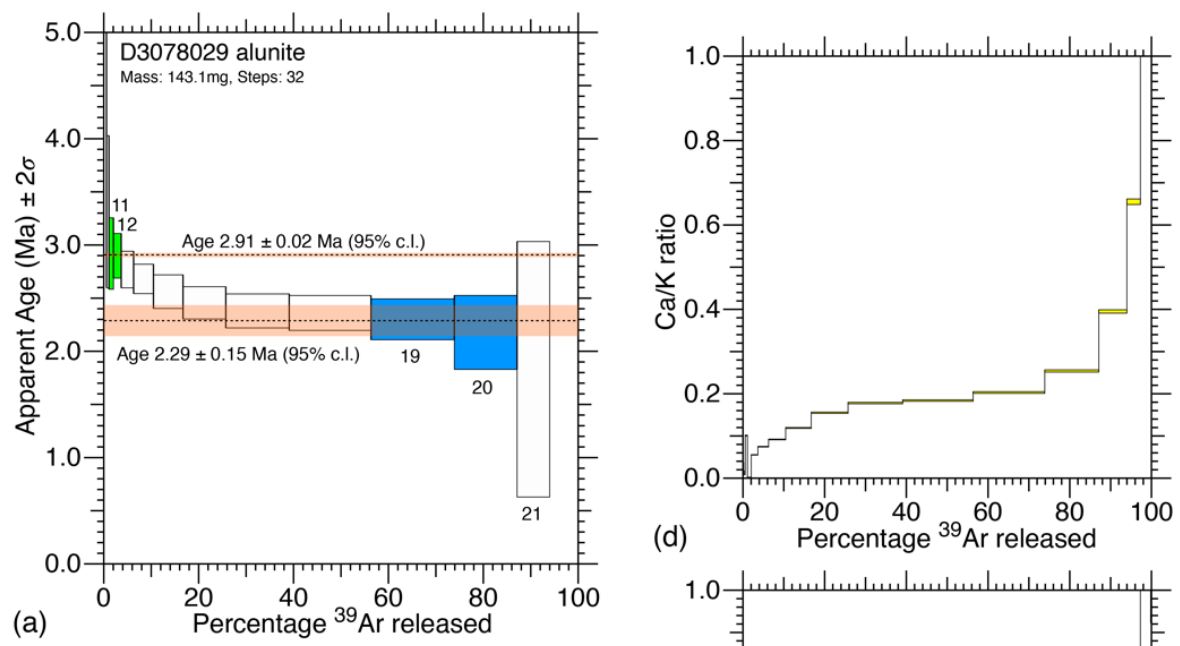

(a)
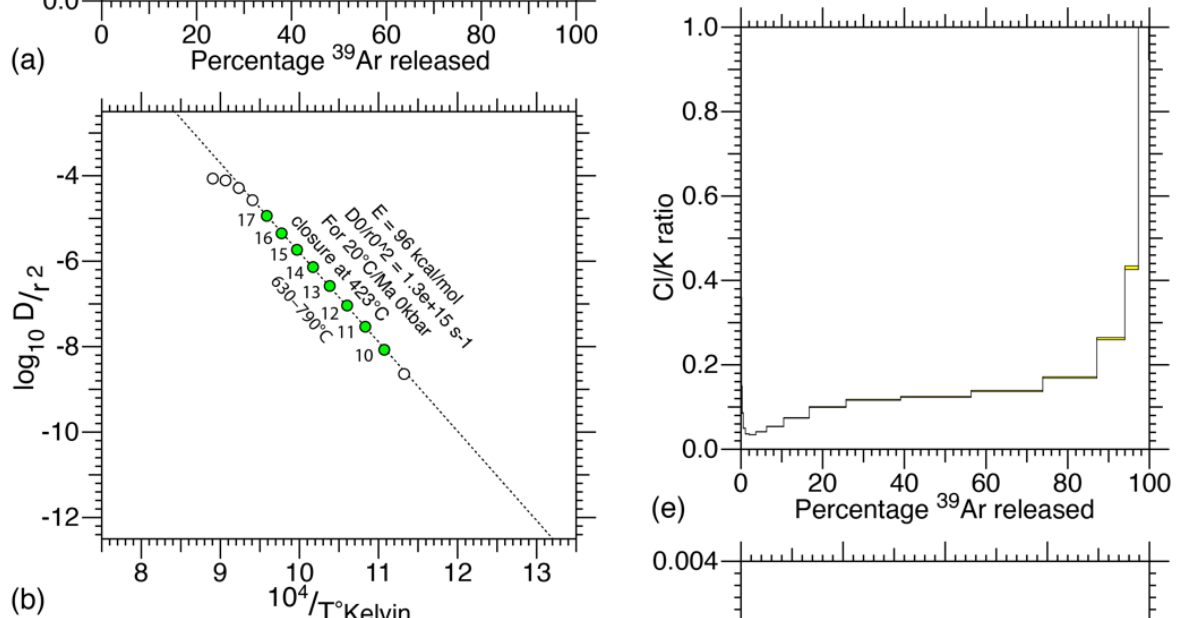

(b)
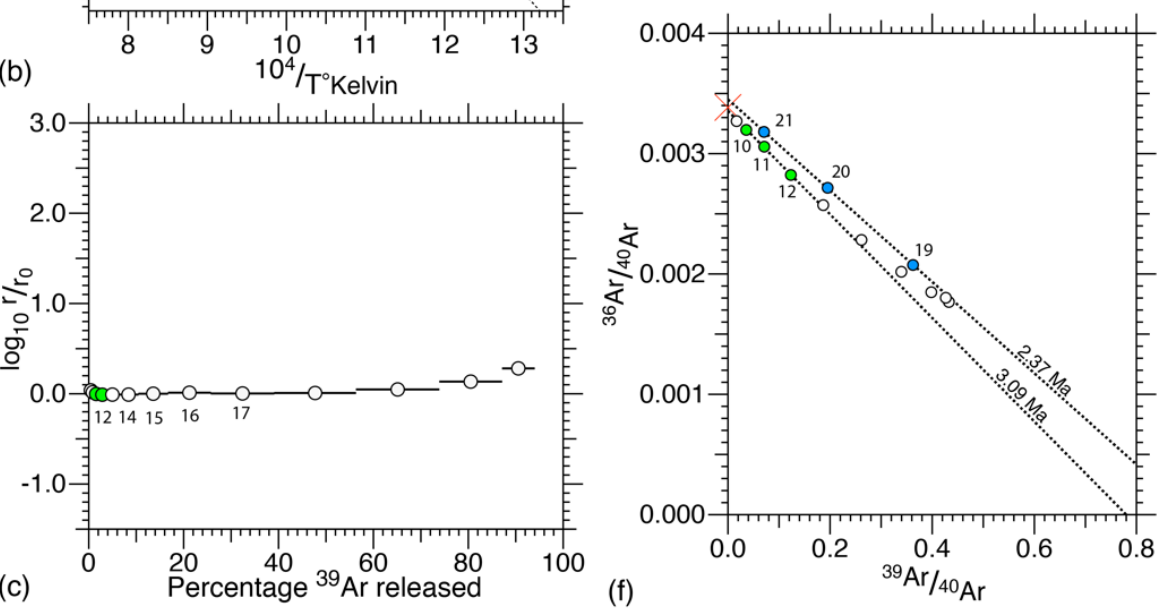
Figure 8 Data from sample D3056884, plotted using the eArgon program: (a) the age spectrum with two distinct plateau segments; (b) the Arrhenius Plot with one distinct diffusion domain, and then mixing over a range, with estimated closure temperatures; (c) a comparative radius plot, which shows 195 the relative volumes; (d) the $\mathrm{Ca} / \mathrm{K}$ ratio inferred from the release of ${ }^{37} \mathrm{Ar}$; (e) the $\mathrm{Cl} / \mathrm{K}$ ratio inferred from the release of ${ }^{38} \mathrm{Ar}$; and (f) the York Plot which shows two inverse isochrons.

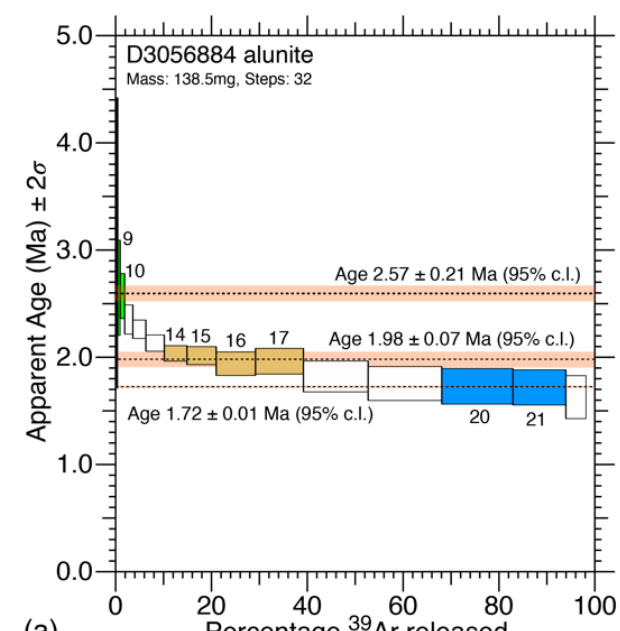

(a)
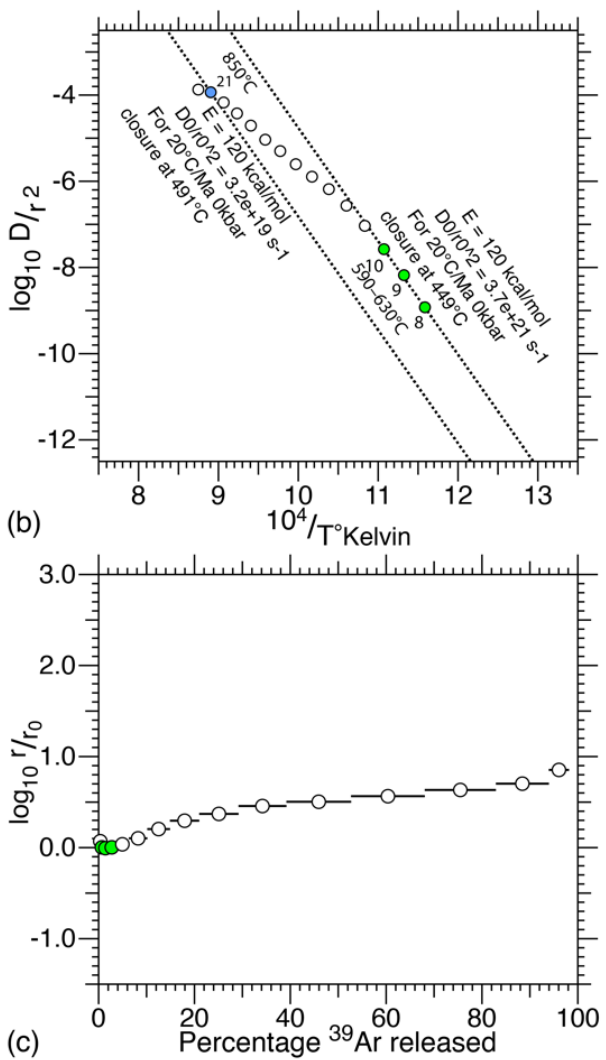

(d)
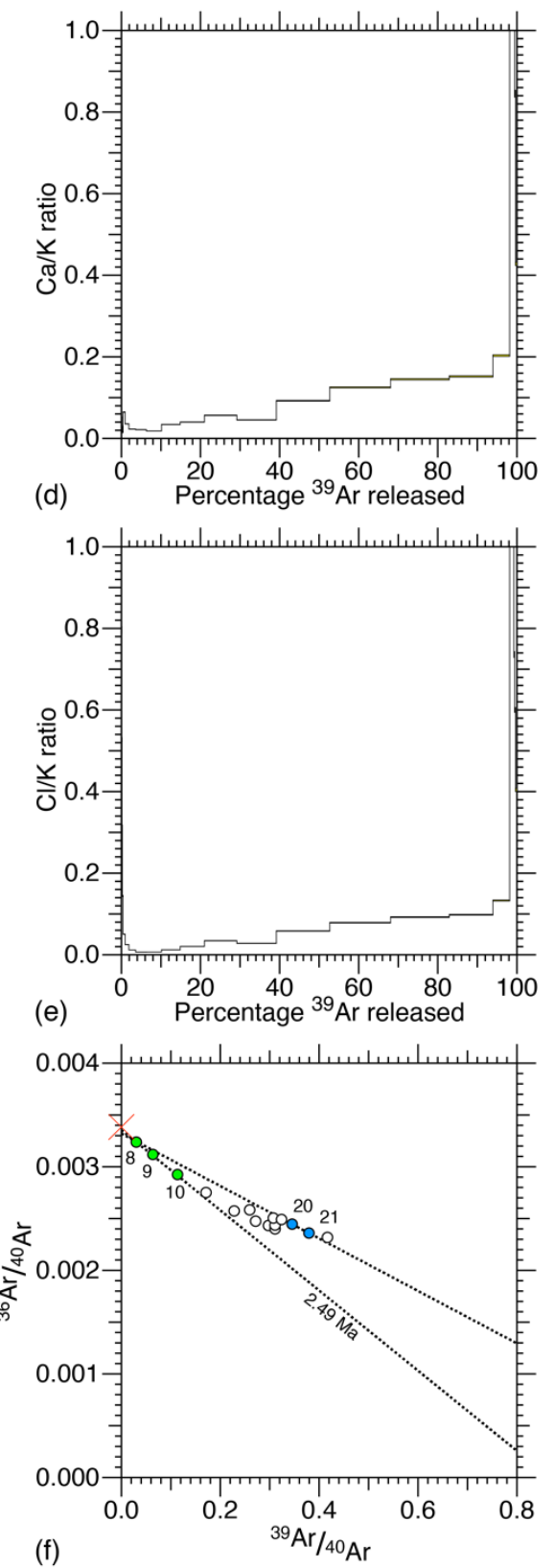
Figure 9 Data from sample D3049860: (a) the age spectrum with one plateau segment followed by mixing towards a lower asymptote; (b) the Arrhenius Plot, with two similar diffusion domains, estimated closure temperatures as shown; (c) a comparative radius plot, which shows the relative volumes of the two domains; (d) the $\mathrm{Ca} / \mathrm{K}$ ratio inferred from the release of ${ }^{37} \mathrm{Ar}$; (e) the $\mathrm{Cl} / \mathrm{K}$ ratio inferred from the release of ${ }^{38} \mathrm{Ar}$; and (f) the York Plot which shows one inverse isochrons, and then mixing toward the limit in the age plot. See text for further detail.
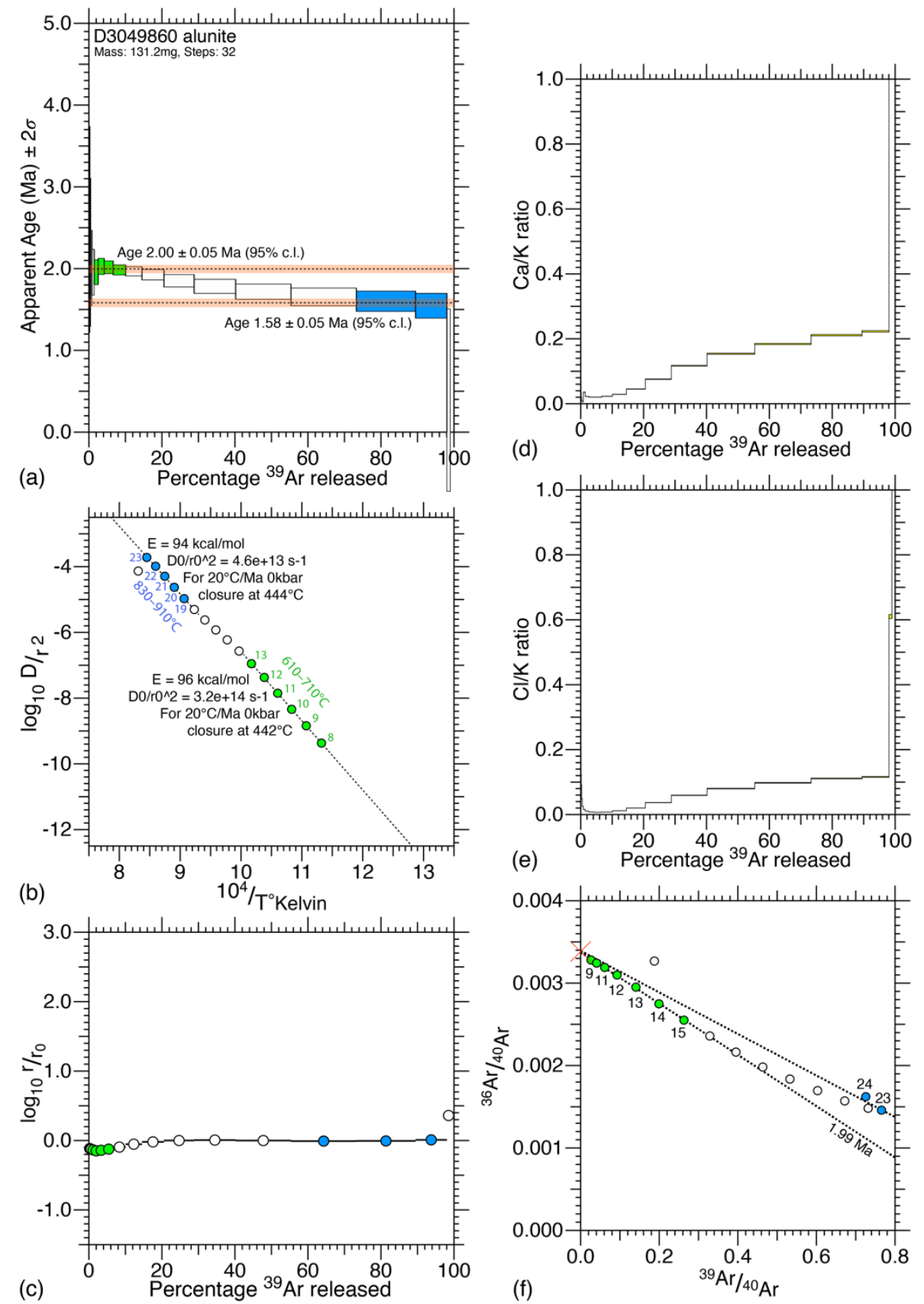
205 Figure 10 Data from sample D3137821: (a) the age spectrum with two plateau segments identified; (b) the Arrhenius Plot, with two diffusion domains, estimated closure temperatures as shown; (c) a comparative radius plot, showing the relative volumes of the two domains; (d) the $\mathrm{Ca} / \mathrm{K}$ ratio inferred from the release of ${ }^{37} \mathrm{Ar}$; (e) the $\mathrm{Cl} / \mathrm{K}$ ratio inferred from the release of ${ }^{38} \mathrm{Ar}$; and (f) the York Plot which shows two inverse isochrons, one not apparent in the age plot.
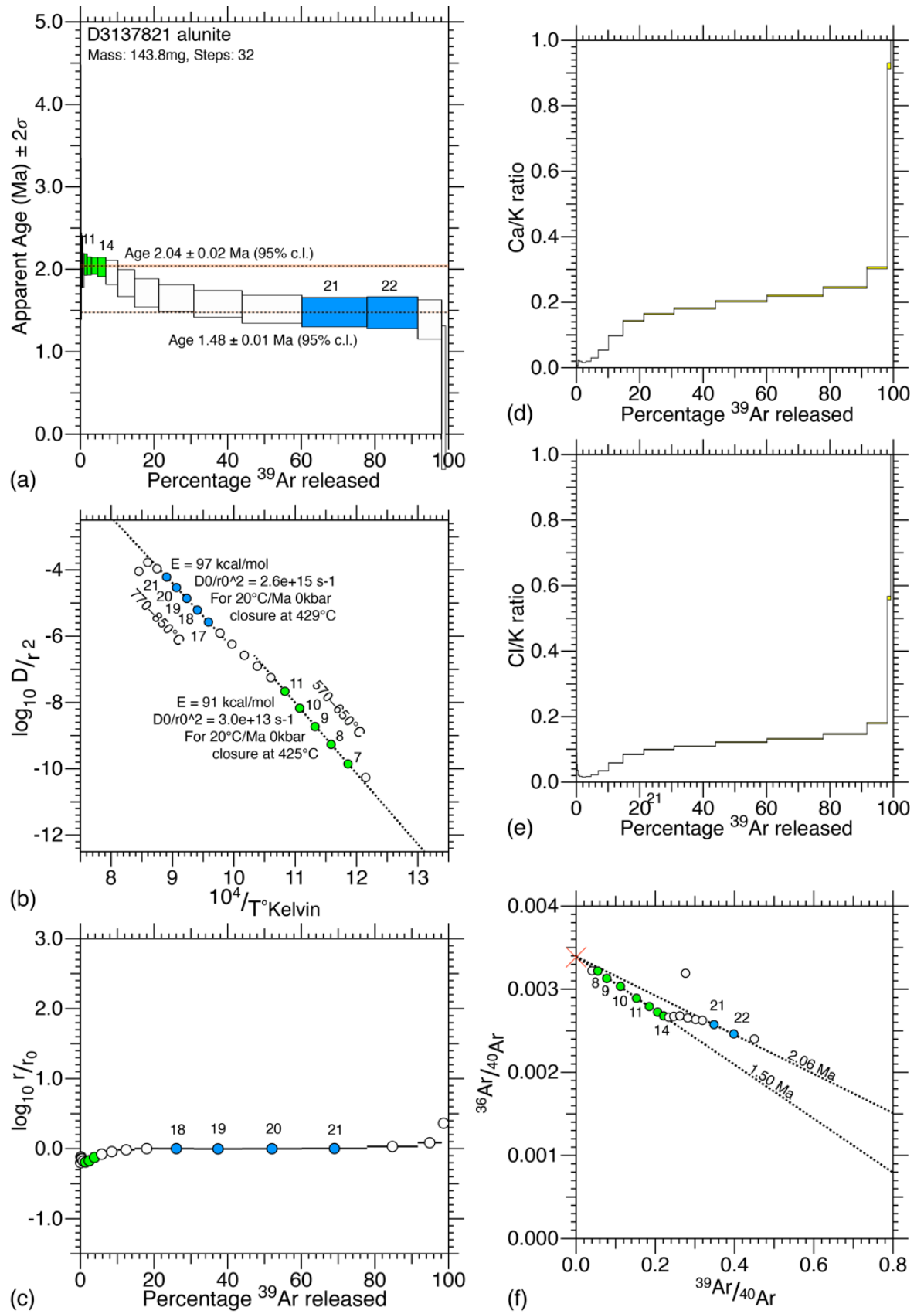
Figure 11 Data from sample D3150595, plotted using the eArgon program: (a) the age spectrum with limits identified; (b) the Arrhenius Plot, which allows recognition of one diffusion domain, estimated closure temperature as shown; (c) a comparative radius plot, which shows the relative volumes; (d) a plot of the $\mathrm{Ca} / \mathrm{K}$ ratio inferred from the release of ${ }^{37} \mathrm{Ar}$; (e) a plot of the $\mathrm{Cl} / \mathrm{K}$ ratio inferred from the 215 release of ${ }^{38} \mathrm{Ar}$; and (f) the York Plot which shows one inverse isochron, then mixing toward the limit shown in the age plot. See text for further detail.
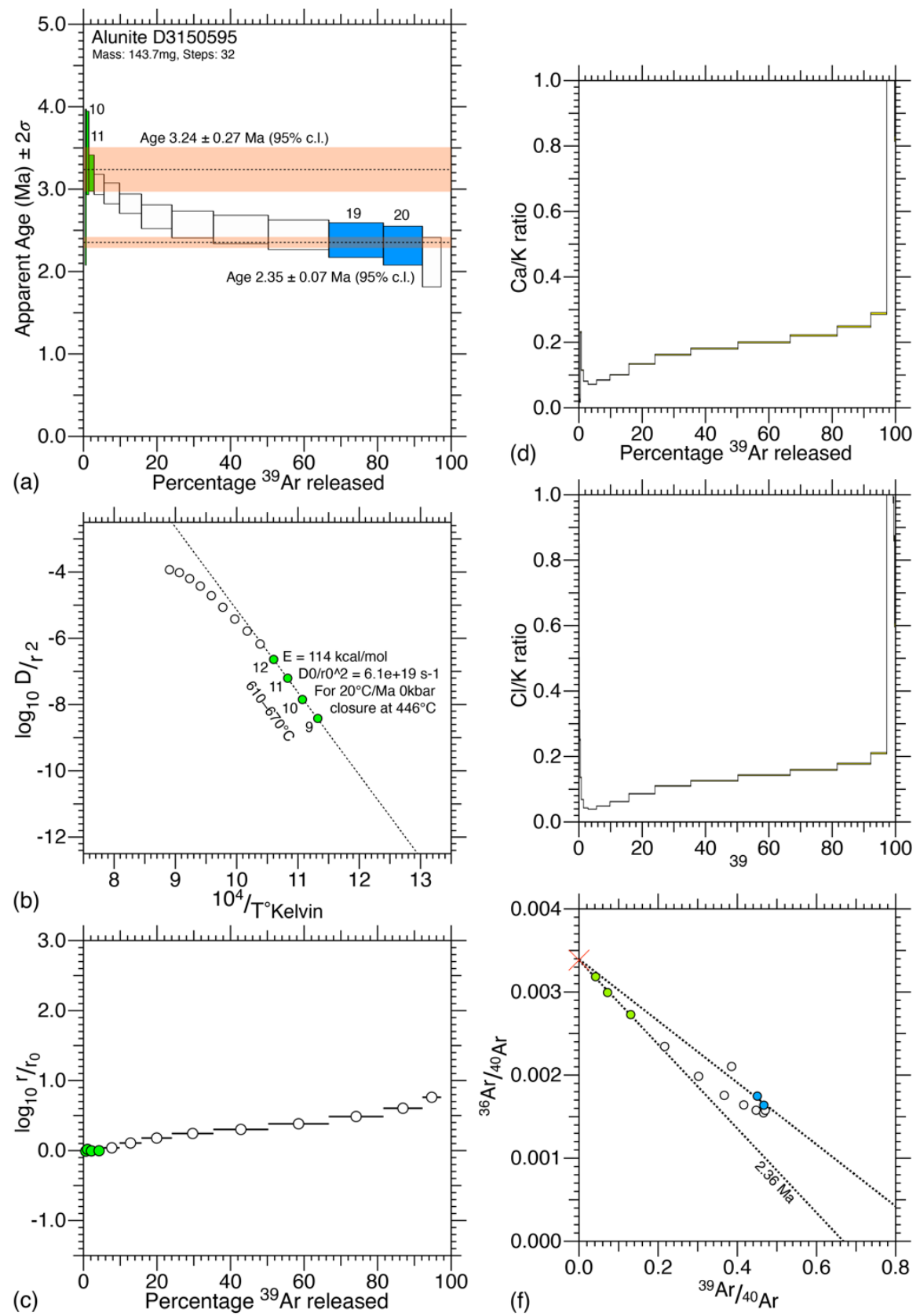
Figure 12 Data from sample D3067305, plotted using the eArgon program: (a) the age spectrum with one plateau segment; (b) the Arrhenius Plot, with one diffusion domain, estimated closure temperature as shown; (c) a comparative radius plot; (d) a plot of the $\mathrm{Ca} / \mathrm{K}$ ratio inferred from the release of ${ }^{37} \mathrm{Ar}$; (e) a plot of the $\mathrm{Cl} / \mathrm{K}$ ratio inferred from the release of ${ }^{38} \mathrm{Ar}$; and (f) the York Plot which shows one inverse isochron. See text for further detail.
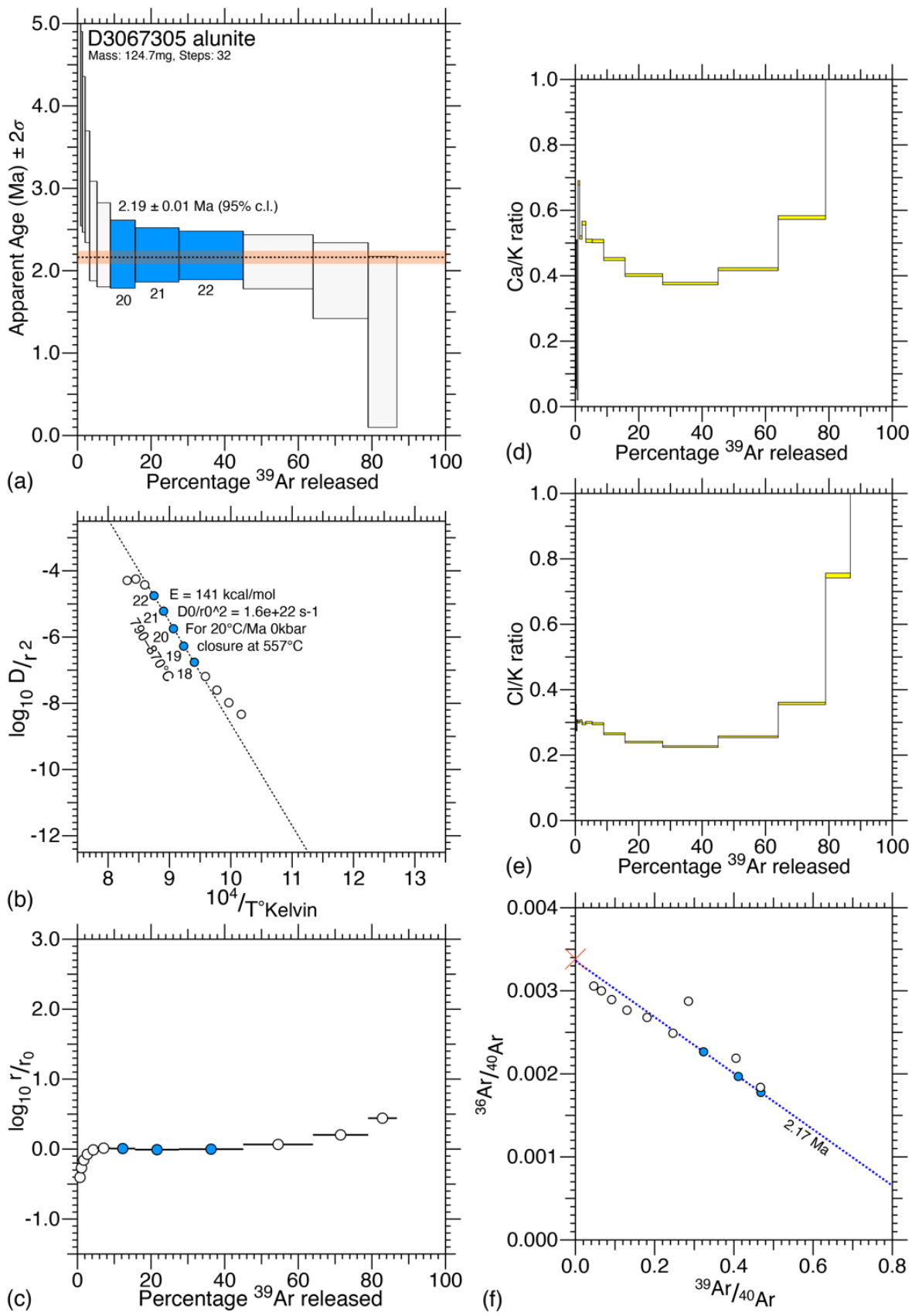
These are the first detailed ultra-high-vacuum (UHV) furnace-step-heating results for alunite that have been reported in the literature, and hence we consider that some detail in our analysis is of general benefit to specialists and non-specialists alike. The age spectra illustrated have some common aspects: i) they are not simple plateaux; ii) their morphology involves an upper limit OR a plateau segment in the first few percent (up to 10\%) of ${ }^{39}$ Ar release; iii) the spectra display an asymptotic decrease in age towards a towards a lower limit (which is sometimes a plateau segment); iv) the last few percent of ${ }^{39} \mathrm{Ar}$ release is marked by a reduction in apparent age, because of mixing with a $\mathrm{KCl} / \mathrm{CaCl}_{2}$ gas reservoir derived from inclusions (?). All of the age spectra show evidence of contamination in the first steps, with high initial ages that decrease, often to a small plateau age segment. Furthermore, during the last steps of each of the heating schedule there is significant contamination with decrease towards a zero-age gas reservoir, which is evident in all York Plots. Our analysis (Figs. 3-12) shows this is because of mixing with a gas reservoir most likely released from inclusions that contain $\mathrm{KCl}$ and $\mathrm{CaCl}_{2}$. In many cases, early steps define the most retentive diffusion parameters for alunite. We can recognise contamination because otherwise concordant release of ${ }^{39} \mathrm{Ar}$ is reflected in concordant release of ${ }^{40} \mathrm{Ar}$.

\subsection{Ultra-high-vacuum (UHV) ${ }^{39} \mathrm{Ar}$ diffusion experiments}

Ultra-high-vacuum (UHV) ${ }^{39} \mathrm{Ar}$ diffusion experiments were conducted on all samples while ${ }^{40} \mathrm{Ar} /{ }^{39} \mathrm{Ar}$ geochronology was carried out. The total release of ${ }^{39} \mathrm{Ar}$ was recorded and summed to provide a percentage release table. Since ${ }^{39} \mathrm{Ar}$ is produced only during neutron irradiation, its initial distribution can be assumed to be uniform within the lattice, except where recoil has driven ${ }^{39} \mathrm{Ar}$ loss. The diffusivity during each heating step during the UHV experiment can therefore be ascertained by the application of analytical formula (listed in Forster \& Lister, 2014) to compute the normalised diffusivity

$245\left(\mathrm{D} / \mathrm{a}^{2}\right)$ that can achieve the measured percentage loss. This enables the computation of the Arrhenius data as shown in Figures 3-12. The accompanying comparative radius plots requires the assumption that activation energy does not vary between diffusion domains. Therefore, a reference domain is chosen for comparison, noting the $\log \left(\mathrm{r} / \mathrm{r}_{0}\right)$ plot that follows in consequence depends on this assumption.

The Arrhenius plot can be analysed by the selection of lines that divide the population by rank order. Such dividing lines obey the Fundamental Asymmetry Principle (or FAP) recognised by Forster \& Lister (2010) and allow estimates for the activation energy of individual diffusion domains. This is a mathematical result that must be applied if one assumes argon loss takes place only as the result of solid-state diffusion without microstructural modification. In complex cases, Forster et al. (2015) showed that detail in the Arrhenius plot allowed estimates of activation energy domain by domain. They set out examples that are useful guidelines in MDD analysis, which rules are followed here. The effect of recoil influences these estimates, but only for the initial steps. Since thermal neutrons are largely responsible, the effect of recoil can be simulated by considering the effect of a short heat pulse prior to the start of the experiment. Since the ${ }^{39} \mathrm{Ar}$ thereby released is not taken into account during the subsequent UHV experiment, the initial steps will underestimate diffusivity, with a gradual decrease in the difference between the 'real' value and that mesasured during the experiment. Luckily, the stepheating experiments we used involved isothermal steps. The first step will always involve an estimate of diffusivity that is equal or greater to that obtained in the second step, except when recoil has caused prior argon loss. Therefore, there is an easy way to recognise which of the initial steps not to consider when attempting to invert Arrhenius data to obtain estimates for the responsible diffusion parameters. 


\subsection{Arrhenius data and closure temperature estimates}

To demonstrate the significance of the ages obtained, it was necessary to evaluate the diffusion properties of alunite, to allow an estimate of likely closure temperatures. An age spectrum reflects either the age at which a mineral or domain grew or was reset by grain boundary migration, or when the mineral system cooled below its closure temperature. For rapid cooling, the closure temperature marks the point at which diffusion of a daughter product out of the mineral system becomes sufficiently slow as to be safely ignored. The daughter isotope, in this case ${ }^{40} \mathrm{Ar}$, thereafter accumulates in the mineral lattice. However, the closure temperature is not a single well-defined temperature, but a complex range which can differ between domains even within a single crystal. Estimates for closure temperature are thus important to understand the context of age data. Since epithermal deposits form at temperatures ranging from $200-350^{\circ} \mathrm{C}$ (White and Hedenquist, 1990), retentive alunite could yield growth ages. Conversely, if alunite is unretentive, the age would indicate when the deposit cooled, and alunite could not be able to be used to distinguish different overprinting fluid systems.

Closure temperature can be determined from Arrhenius plots as outlined by Dodson (1973). Arrhenius plots take the inverse of absolute temperature from each step of the heating schedule along the $\mathrm{x}$-axis and logarithm of $\mathrm{D}_{0} / \mathrm{r}^{2}$, where $\mathrm{D}_{0}$ is diffusivity and $\mathrm{r}$ is the radius of the diffusion domain, on the $\mathrm{y}$-axis (McDougall, 1999). According to Lovera et al. (1997) the Arrhenius plot should display a single straight line, when dealing with a single diffusion domain. From this line we can determine the diffusion paraments (i.e., activation energy and frequency factor) and calculate closure temperature by inferring diffusion geometry and assuming cooling rates were faster than $20^{\circ} \mathrm{C}$ per million years.

285 There has been much debate around interpretation of Arrhenius data. Forster and Lister (2010) simulated artificial step-heating experiments in order to establish a consistent methodology for interpreting Arrhenius plots, especially those that do not produce linear arrays. From this work came the Fundamental Asymmetry Principle (FAP) which provides an objective guideline for the analysis of Arrhenius plots. Simply put, line used to estimate diffusion parameters must divide the sequence of

290 steps in the Arrhenius plot by rank order. Points of a higher rank order will lie on or to the left of the line and points with a lower rank order with lie on or to the right of the line. The FAP and the need to well populate the Arrhenius plots particularly in the lower temperature of the experiment is absolutely critical in gaining closure temperature data and in allowing modelling.

Using these methods, we analysed the Arrhenius plots from our alunite step-heating experiments, using the eArgon software (Figs. 3-12). By applying the FAP it was found that the activation energy ranges between $370-660 \mathrm{~kJ} / \mathrm{mol}$ (or $89-157 \mathrm{kcal} / \mathrm{mol}$ ), with closure temperature estimates between $400^{\circ} \mathrm{C}$ and $560^{\circ} \mathrm{C}$ for cooling rates of $20^{\circ} \mathrm{C} / \mathrm{Ma}$. Therefore, given the temperatures involved in epithermal mineralisation, these alunite samples were able to accurately determine the age of crystallisation in the various fluid systems involved.

\subsection{Probability Curve Analysis of Frequently Measured Ages (FMAs)}

To determine the periods of alunite growth, each determined plateau, asymptote or limit point was plotted using a Gaussian distribution to smooth the data (Fig. 13). Several distinct periods of alunite 
growth could thereby be distinguished across the 10 samples measured in this study. The oldest events recorded occurred between $\sim 2.9-3.5 \mathrm{Ma}$. The dominant events occurred at $\sim 2.25$ and $2.00 \mathrm{Ma}$. Younger growth events occurred at $\sim 1.70$ and $1.50 \mathrm{Ma}$. Since the alunite measured was retentive, these FMAs must therefore be interpreted to reflect the existence of several distinct and separate very short-lived periods of alunite growth during the history of alteration and mineralisation.
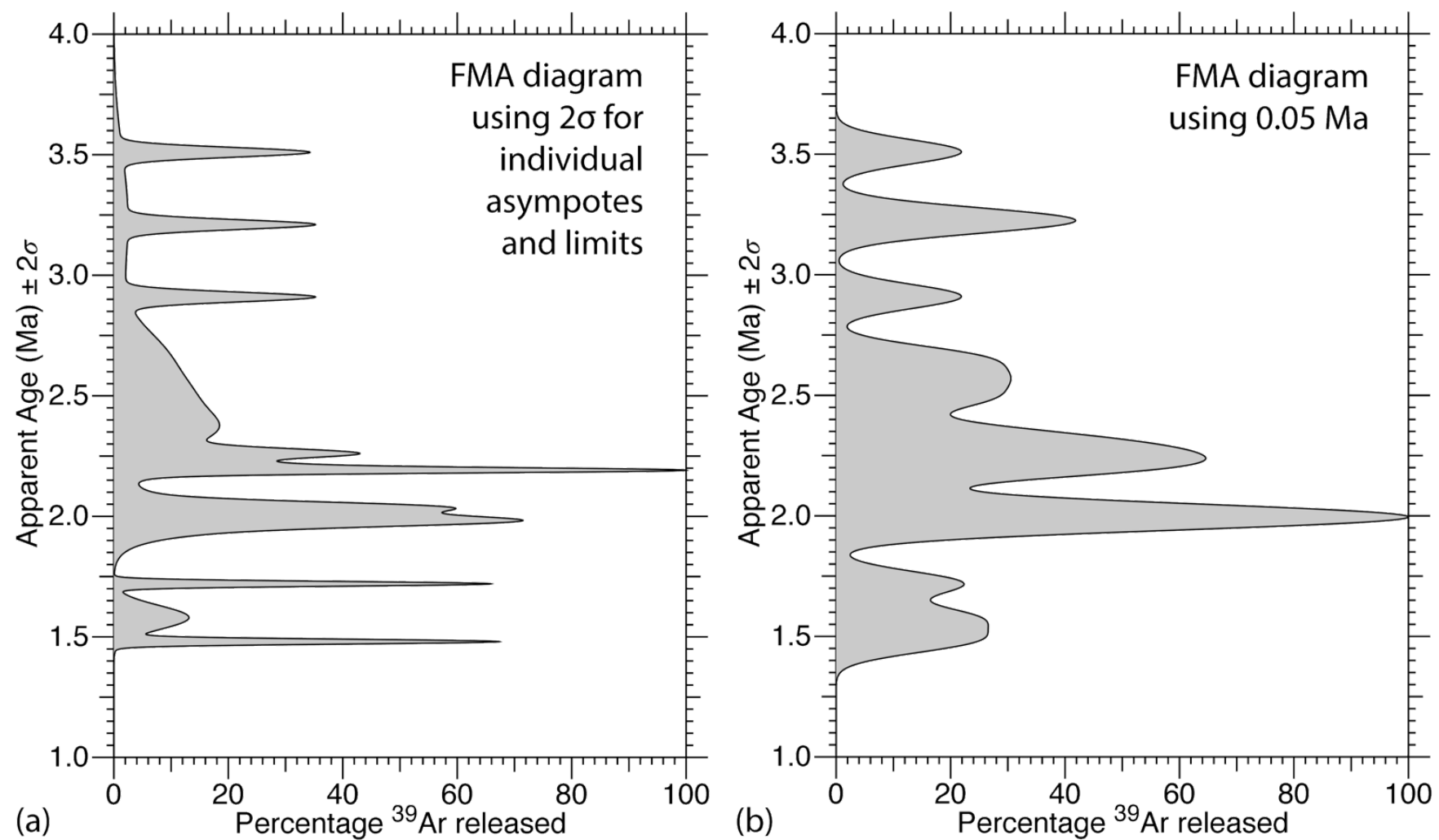

Figure 13. Gaussian distributions used to develop a probability curve showing Frequently Measured Ages (FMAs) based on the application of the method of asymptotes and limits to the measured age spectra. The data utilised is as shown on individual age plots: (a) utilised uncertainties individually estimated for the scatter of the mean of each plateau segment, limit or asymptote; (b) imposed a fixed uncertainty on each plateau segment, limit or asymptote.

\section{Discussion}

\subsection{The role of the plateau in age spectrum}

In review, a previous version of this paper attracted negative attention because the age spectra presented are not simple plateaux. One reviewer wrote that: "Numerous criteria have been put forth over the last several decades to evaluate age spectra and to calculate a plateau age (e.g., Fleck et al., 1977; Sharp and Renne, 2005; Jourdan et al., 2004). In a recent paper consisting of forty ${ }^{40} \mathrm{Ar}{ }^{\beta 3} \mathrm{Ar}$ specialists from around the globe, the following criteria were put forth for a plateau." It must: "(1) consist of at least 
five or more consecutive steps that comprise at least $>50 \%$ of the ${ }^{39}$ Ar released; (2) not have a slope (i.e., the majority of consecutive plateau steps do not have ascending or descending ages; Sharp and

325 Renne, 2005); and (3) have an isochron regressed through all of the plateau steps with a $\left({ }^{40} \mathrm{Ar} /{ }^{36} \mathrm{Ar}\right)$ intercept that is indistinguishable from the atmospheric value at the $95 \%$ confidence level. It was pointed out that very few of the age spectra presented here have a plateau that fits these criteria. Some authors take this further, e.g., Li et al. (2020) argue that an age spectrum is not reliable unless it approximates a plateau and recommend that such 'imperfect' results be discarded.

330 The present authors do not agree with this notion. There is no theoretical reason that justifies rejection of an age spectrum because the data does not define a simple 'plateau'. In fact, except under the most restrictive of circumstances, there is no reason at all to suppose that the morphology of an age spectrum should ever approximate a simple plateau. One might set out reasonable conditions for a filter (as noted above) to reject imperfect data, but this can be done only for circumstances when there are objective reasons a priori to assume that ${ }^{40} \mathrm{Ar} /{ }^{39}$ geochronology should produce a simple plateau. Otherwise, should data that does not fit an author's preconceptions be hidden from view? A better course might be to work out why some spectra are complex, and why others are not. If we find a solution to this question, then what should concern us is how we can modify the theory and practice of argon geochronology to deal with such complexity.

340 There are circumstances that will produce an age spectrum defined by a simple plateau, e.g., the analysis of rapidly quenched glass (caused either by volcanic eruptions or alternatively, by meteorite impact). Erupted volcanics may also rapidly cool and thus yield a well-defined plateau determining a 'cooling age'. Plateaux are also to be expected for minerals grown at temperatures well below those at which diffusion of argon becomes significant.

345 There are also instrumental and methodological reasons that cause a particular measurement to end up looking like a plateau, e.g., the use of laser without the ability to control sample temperature will often produce a 'scattergram', but this data should not be compared with or referred to as a step-heating experiment in any case. The detail of a spectrum can also be lost by starting the measurement sequence at too high a temperature (e.g., Kula et al. 2012), or by omitting the long cleaning times that are necessary to remove volatiles prior to commencing measurement. Starting to measure at too high a temperature may result in sample breakdown, ensuring chaos in terms of the sequential release of argon during the progress of the experiment. It is rare for a laboratory to have the technical capability to conduct step-heating experiments, since the list of requirements includes such items as the ability to exert precise control on temperature variation with time, and the capacity for forced cooling that is required to mimic a temperature-time 'square wave' during heating steps.

\subsection{Dealing with the natural complexity of an age spectrum}

To deal with complexity, we need to develop new techniques, e.g., as attempted by Forster and Lister (2004) when they outlined the method of asymptotes and limits for the analysis of complex ${ }^{40} \mathrm{Ar} /{ }^{39} \mathrm{Ar}$ age spectra. They then determine the list of Frequently Measured Ages (FMAs) and search for (and correlate the age spectrum with) microstructural processes that allow explanation of the event that an individual FMA might represent. There are considerable advantages in utilising this method, and it has 
been implemented in a number of studies, in various locations and geological environments (e.g., Chiu et al. 2018; Forster et al., 2014, 2019; Forster \& Lister 2009; Ghanem et al. 2016; Pownall et al. 2017; Stenhouse et al. 2014; Viete et al. 2016, Beltrando et al., 2009). In all cases, the method has yielded consistent results. Other statistical approaches offer promise (e.g., Carter et al., 2020). These developments offer the potential to broaden and diversify theory and practice in argon geochronology.

The route we have chosen (illustrated in this paper) is fourfold: i) prior to measurement, to rid samples of volatiles by prolonged warming under ultra-high-vacuum (UHV) conditions at temperatures below the point at which any significant percentage of the ${ }^{39} \mathrm{Ar}$ stored in the mineral lattice begins to be released; ii) by using carefully chosen temperature-time schedules (determined a posteriori by dint of experience with any given sample set) to ensure that as uniform as possible a release of ${ }^{39} \mathrm{Ar}$ in each heating step takes place; iii) while, at the same time, a distribution of temperature is maintained (amongst the steps that allow meaningful release of ${ }^{39} \mathrm{Ar}$ aliquots) to ensure as uniform as possible a distribution of points on the $1 / \mathrm{T}^{\circ} \mathrm{K}$ axis of an Arrhenius plot; iv) taking note of the above, choosing

375 sample size (dependent on age and potassium content) so that the chosen steps for a particular experiment are able to liberate very many different age data points.

In this way we have been able to provide unprecedented detail in measured age spectra, and therefore avoid the pitfalls that accompany laser-produced 'scattergrams' or 'pseudo-step-heating' experiments that offer no actual control of temperature except in that each of the relatively few steps that are measured is potentially either hotter or of longer duration than those that precede it. The use of a properly calibrated resistance furnace is essential in that such equipment offers rigorous (and documented) temperature control, while forced-injection of chilled cooling water through the assembly at the end of a period of heating (in this case 15 minutes) ensures the very rapid cooling that is essential in allowing the temperature-time history in each measurement step to approximate a square wave.

385 Otherwise, it is difficult to justify the use of analytical solutions in inferring diffusivity $\left(\mathrm{D} / \mathrm{a}^{2}\right)$ where ' $\mathrm{a}$ ' is the radius or dimension of the diffusion domain. The production of detailed age spectra is essential in our view, since without many steps, it is difficult to consider the effects of such variables such as: i) argon recoil during neutron irradiation, during the early steps of the UHV diffusion experiment; or ii) the effect of mixing with impurities such as $\mathrm{KCl}$ and $\mathrm{CaCl}_{2}$ in inclusions (in the case of the present results) during the final steps of the UHV diffusion experiment. Thus, when complex age spectra are obtained, one can be sure they are meaningful by relying on the detail provided by the many subsequent heating steps. A laser scattergram will not suffice, nor step-heating experiments that produce too few steps to reveal the necessary morphological detail as to how a spectrum looks.

\subsection{What causes a complex age spectrum?}

395 Complex age spectra result when there are different types of gas reservoirs in the aliquot of mineral grains analysed during the step-heating experiment. Typically, this occurs because: i) there is more than one microstructural domain; and ii) the microstructure/microchemistry of individual domains requires different diffusion parameters, and these govern differing patterns of ${ }^{39} \mathrm{Ar}$ release during the experiment; or iii) when one domain degasses differently because of microstructural change and/or breakdown as temperatures increase in sequential steps. Because so many heating steps were 
undertaken, we were able to compare the age spectra with graphs showing the variation of different isotopic ratios: i) the $\mathrm{Ca} / \mathrm{K}$ and $\mathrm{Cl} / \mathrm{K}$ ratios, which showed a gradual increase during the experiment, until a sudden rise during the final steps; ii) the Arrhenius plots and the linked $\log r / r_{0}$ plots, which allow recognition of distinct diffusion domains, their relative volumes, and estimates of the relevant diffusion parameters; and finally iii) the York plot which allows recognition of inverse isochrons, if they are present, but more importantly, which allow the progression of mixing between different gas reservoirs during the experiment to be monitored and examined.

Because the experiments were designed to allow many (32-35) steps we were also able to compare the diffusion parameters inferred for steps in one part of an age spectrum with the parameters inferred for

410 other steps in all segments of the age spectrum. In all cases these differences in the inferred diffusion parameters from one domain to another were directly inferred from the measured isotope data, and explicitly related to the observed pattern of variation in the measured age spectra. This is not to say that the inferred diffusion parameters are those that applied in the natural environment! Such an assumption relies on metastability during the furnace step-heating episodes (in this case each relatively short in

415 duration). However, since variation in the age spectra invariably correlates with different domains in the Arrhenius plot, we can be certain that the observed variation reflects age patterns that map onto the same microstructural domains. Since these domains reflect growth ages, we can be sure that we have identified different and distinct periods of hydrothermal mineral growth in the natural environment.

The results that were obtained make good sense. Overprinting fluids active in the formation of Martabe 420 Gold deposit produced alunite in several growth generations, with variation in mineral geochemistry ensuring slightly different diffusion parameters. These differences enabled discrimination of these various generations during UHV diffusion experiments. Multiple plateau segments and/or asymptotes are therefore a natural complication to be expected in the resultant ${ }^{40} \mathrm{Ar} /{ }^{39} \mathrm{Ar}$ age spectra, thus deprecating methods reliant on the existence of simple 'plateaux'. The measured age spectra appear to result from fine intergrowth of diffusion domains in one mineral grain, or even the intergrowth of different mineral grains. The microstructural detail is finer than can be teased out using laser spot analysis. Because the problem is multi-scalar, the age spectra are likely not to be resolvable without the benefit of carefully designed UHV diffusion experiments.

\subsection{The benefits in using the method of asymptotes and limits}

430 As shown in this paper, the otherwise hidden detail of an age spectrum can be liberated by carefully choosing the heating steps to allow the maximum number of meaningful episodes of gas release, noting that temperature and time for each heating step must be chosen to ensure as uniform an aliquot (of the

${ }^{39} \mathrm{Ar}$ released in each heating step) as is possible. At the same time, decisions as to the distribution of temperature amongst the subsequent heating must be chosen so to ensure as uniform as possible a

435 distribution of points on the $1 / \mathrm{T}^{\circ} \mathrm{K}$ axis of an Arrhenius plot. Steps that allow meaningful release of ${ }^{39} \mathrm{Ar}$ aliquots vary with the applied temperature. Steps that allow a uniform distribution on an Arrhenius plot vary with the inverse of temperature. Mathematically the problem posed can be compared to the construction of a "devil's staircase" [or a Cantor function]. 
Irrespective of whether there was loss of argon from the mineral lattice as the result of diffusion in the natural environment, what is recorded in the mass spectrometer depends critically on the pattern of argon gas release from the different microstructural domains, governed by the difference in their diffusion parameters. As noted by a previous reviewer "Almost all of the Muston et al spectra have a significant slope. Only one sample (D3035222) has a plateau based on the Schaen et al (2020) criteria". This is because the diffusion parameters are sufficiently similar as to require mixing of gas 445 from typically two (but sometimes three) of the corresponding microstructural domains. In only few cases are separate plateau segments recognizable. The spectra typically display an asymptotic decrease in age towards the age of the most retentive domain, the age of which is therefore readily distinguished by application of the method of asymptotes and limits.

Analysis of mixing using the age spectrum illustrates but one of the considerable advantages gained through application of the method of 'asymptotes and limits'. Based on the theory of mixing gas from different microstructural and/or microchemical reservoirs, the same result can be obtained by analysing the York Plot in this context. Because the step-heating schedule produces so many well-populated steps, it is possible to use such plots to track the progression of mixing of different gas reservoirs. In Figure 5, we see first the release of air, moving progressively towards the gas reservoir defined by the lattice of

455 domain A. Thereafter there is a short period during which heating steps release gas from domain B, but thereafter the trend returns to that defined by the mixing line between air and domain A. Interestingly, this is followed by a sharp loop and the York Plot records mixing with gas from a small-volume reservoir that may well be defined by $\mathrm{KCl}$ and $\mathrm{CaCl}_{2}$ salts, which begin to melt around $770^{\circ} \mathrm{C}$, or more complex combinations including with carbonate, for which there is no data.

460 Such interferences could possibly be removed by washing samples in acid baths, but we did not undertake such effort, because of the likely damage to existing microstructure. Instead, we relied on the detail provided by heating schedules that produced many steps, thereby enabling recognition of mixing lines, in this case with a low volume reservoir that affects only the last steps in the sequence, reducing their apparent ages. Typically, those steps are associated with age errors two orders of magnitude of more times the average, and therefore not sensibly taken into account. We can recalculate the ages of the affected steps using the ${ }^{39} \mathrm{Ar} /{ }^{40} \mathrm{Ar}$ intercept defined by the isochron that shows the mixing that has taken place with this low relative volume reservoir, but this did not alter our conclusions.

The final step in the application of the method of asymptotes and limits is that the cumulated results of each assessment are plotted using a Gaussian statistic, to generate a probability curve. This enables determination of the probable significance of the inferred plateau segments, or of the asymptotes and limits identified. If the dataset is sufficiently robust, with a sizeable number of samples, statistically significant Frequently Measured Ages (FMAs) can be recognized. Hence our conclusion that there were in fact multiple distinct alunite growth events. In the present application, perhaps there are too few samples to be certain, but the Frequently Measured Ages (FMAs) that have been recognised using 475 Gaussian probability plots can be shown to be statistically significant using Poisson statistics: it is highly improbable that coincidences in the determined ages are the result of random processes.

The question then arises as to why asymptotes and limits recognised should be consistent amongst the sample set. The answer seems self-evident: different short-lived episodes of mineral growth have taken 
place at distinctly different times. Given the retentivity of alunite (which was demonstrated by the UHV diffusion experiments), it seems therefore reasonable to suggest that the FMAs define distinct periods of growth. Microchemical or microstructural variation might be the reason that different growth episodes produced alunite with different diffusion parameters.

\subsection{Comparison with laser methods}

Laser analyses have not been able to produce the same level of detail and accuracy that is routinely attained during a carefully constructed UHV furnace step-heating experiment. The least successful attempts at laser step-heating are those that use a manually guided laser to roam over a sample, since this produces variable and transient temperature distributions. Laser methods that deny the option for protracting cleaning in situ before beginning measurement cycle are also an issue, since this step that is essential in removing contaminants and therefore a necessary requirement of a carefully designed UHV step-heating experiment.

Laser analysis might be able to analyse less material, but this is not relevant when considering a stepheating experiment designed to release gas in 30-50 steps. We note that an optical pyrometer may inaccurately reflect sample temperature. In any case, Newtonian cooling after laser-heating does not allow the approximation to a square wave occasioned by rapid forced-cooling in a properly designed resistance furnace. Laser methods may also have difficulty in maintaining constant temperature over protracted time periods. There is no reason that laser methods will not overcome these substantial and significant drawbacks. But for the moment, furnace methods have advantages that need to be taken into consideration when setting out to undertake ${ }^{40} \mathrm{Ar} /{ }^{39} \mathrm{Ar}$ geochronology involving complex samples.

Our laboratory uses furnaces that have been specifically designed for UHV step-heating: i) to minimise blanks to low levels by protracted cleaning prior to measurement; ii) to allow calibration of a thermocouple in close contact with the sample, using optical examination of the melting of five different metals in sequence during calibration; iii) to ensure a good approximation to a square wave in temperature-time, which is a pre-requisite for the application of the diffusion equations. Laser methods do not provide such information.

\subsection{Recognising an inverse isochron on a York Plot}

The York Plot is also referred to as an inverse isochron plot, but we avoid such practice since it implies that alignments on such graphs are a priori related to isochrons, which is incorrect. The York Plot is of most value in allowing the inference of different gas reservoirs that mix during the course of a furnace step-heating experiment. In the simplest of all cases (e.g., glass produced during meteorite impact, or a rapidly cooled young basalt) the mixing line between air and the lattice argon will define an 'inverse isochron'. However, even in such simple cases, complexity can be introduced, e.g., a basalt can be altered, introducing a third gas reservoir. In other geological scenarios, the rock may have been reheated, or have cooled more slowly, with the result that a natural progress of age steps in the spectrum masquerades as an 'inverse isochron'. Hence, the use of the inverse isochron plot should be approached with caution since in all but the very simplest of circumstances, any observed alignment of datapoints should not be a priori attributed to the existence of an isochron. 
In any case, the values plotted should be corrected for isotopic interferences occasioned by the presence of calcium and chlorine, utilising the correction factors obtained by including the relevant salts in the canister during neutron irradiation. Otherwise, spurious alignments may result. Excess ${ }^{40} \mathrm{Ar}$ could be inherited by contamination or it could be introduced to the system by fluids at the grain boundary (Kelley, 2002). This can be detected from inverse isotope correlation diagrams by determining the initial ${ }^{40} \mathrm{Ar} /{ }^{36} \mathrm{Ar}$ ratio of the sample (McDougall and Harrison, 1999). However, this method cannot be used for samples with multiple growth generations (e.g., Kunk et al. 2005).

\subsection{Using Arrhenius data to estimate argon retentivity}

525 This study has also shed light on the closure temperature of alunite. There have been previous estimates for the closure temperature of alunite, which have ranged from $\sim 240-320^{\circ} \mathrm{C}$ (Love et al., 1998, Arribas et al., 2011). This is within the temperature range in which epithermal deposits are known to form, i.e., 200-350 ${ }^{\circ} \mathrm{C}$ (White and Hedenquist, 1990). If alunite was so unretentive of radiogenic argon, the ages obtained would represent when the epithermal deposit cooled below the closure temperature rather than 530 when it had formed. It is important, therefore, to emphasize that our results show otherwise, unleashing the potential for alunite geochronology to map different fluid systems formed in a narrow time range.

Key to this effort was the rigorous testing involved in ultra-high-vacuum (UHV) ${ }^{39} \mathrm{Ar}$ diffusion experiments with step-heating schedules designed to allow sufficient detail and spatial coverage in the Arrhenius plot to allow application of the Fundamental Asymmetry Principle (or FAP). Our diffusion experiments produced Arrhenius data that imply closure temperatures between $400^{\circ} \mathrm{C}$ and $560^{\circ} \mathrm{C}$ for modest cooling rates (Figs. 3-12). This indicates that alunite can be highly retentive of argon and thus can be used as a reliable mineral for ${ }^{40} \mathrm{Ar} /{ }^{39} \mathrm{Ar}$ geochronology timing ore deposition in epithermal systems. Radiogenic argon was retained even during later overprinting hydrothermal or magmatic events such as those found in this study.

540 Similarly retentive results were obtained by Ren and Vasconcelos (2019) for some of their samples, although examination of their Arrhenius data reveals several examples in which these authors underestimated the activation energy and associated retentivity. Ren and Vasconcelos (2019) did not apply the FAP (Fundamental Asymmetry Principle (Forster \& Lister 2010) to their analysis. This is a mathematical requirement if multi-domain-diffusion (MDD) models are a priori to be assumed for the analysis. We have scaled their diagrams and applied the FAP and obtained revised estimates for the activation energy are entirely consistent with our results. This is encouraging, for it suggests the methods utilised are relatively robust. In review, we were asked to comment on the difference between their spectra and our own. There is no reason to do this. Perhaps the flat spectra obtained by these authors imply nothing more than that only one generation of crystal growth took place in their samples?

\section{$550 \quad 4.8$ Timing mineralisation episodes in the Martabe mine}

${ }^{40} \mathrm{Ar} /{ }^{39} \mathrm{Ar}$ geochronology has proven to be essential to timing the growth and alteration of minerals in the Martabe gold mine. The first research recognising this was Sutopo (2013) who analysed four alunite samples from the Martabe deposits using ${ }^{40} \mathrm{Ar} /{ }^{39} \mathrm{Ar}$ geochronology. Two of the experiments used the step-heating technique, while the other two used the total fusion age. This research concluded that 
555 alunite grew between 3.30 Ma and 2.0 Ma. Our ${ }^{40} \mathrm{Ar} /{ }^{39} \mathrm{Ar}$ geochronology results for ten samples (Fig. 3) extended the range of the activity in this alteration system to be between $1.40 \mathrm{Ma}$ and $3.48 \mathrm{Ma}$. The measured samples (Figs. 3-12) display complex age spectra, and isolated single plateaux are often not present. The spectra are the result of mixing between radiogenic argon released from alunite grown at different times. Such spectra can be interpreted according to the method of 'asymptotes and limits'

560 (Forster and Lister, 2004), in consequence unveiling the influence of two overprinting alunite forming events in the same age spectrum. This is the first example of overprinting events being recorded in a single step-heating experiment of alunite.

Sample D3011643 produced older events which overlap in timing with the emplacement of the dacite $3.8 \pm 0.5 \mathrm{Ma}$ (dated using the U-Pb method) and andesite $3.1 \pm 0.4$ to $2.8 \pm 0.3 \mathrm{Ma}$ (also dated using the $565 \mathrm{U}-\mathrm{Pb}$ method) flow dome complexes (Sutopo, 2013). The clustering of ages and the overlap with flowdome formation gives us confidence that the interpretation of age spectra using the method of 'asymptotes and limits' is in fact real and not simply an artefact of contamination or excess argon. The younger periods of alteration could be driven by the activity of the Sumatran Fault System, which reactivated fluid pathways. The interpreted fluid systems are shown in Figure 14. More geological

570 information is needed to constrain the alunite alteration systems further, but this is difficult due to the area being covered by dense rain forest and restricted zones. 
https://doi.org/10.5194/gchron-2021-25

Preprint. Discussion started: 13 September 2021

(c) Author(s) 2021. CC BY 4.0 License.
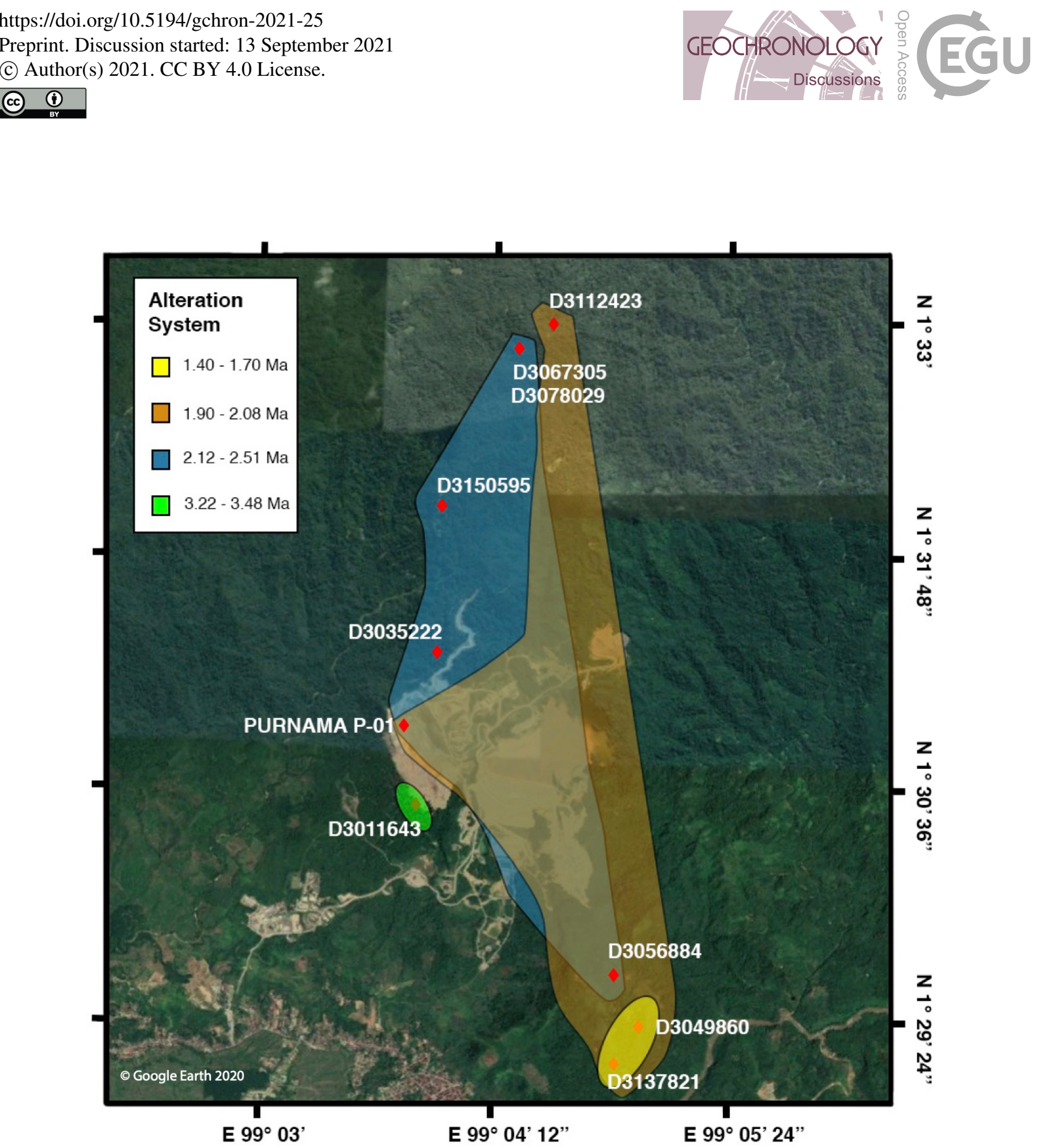

575 Figure 14. Map of Martabe gold field with alteration systems mapped. Alteration systems outlined according to the sample location and period of alunite growth. The two older events are grouped together. 


\section{Conclusion}

Through a detailed and suitable heating schedule, we were able to degas alunite samples without losing

580 a large percentage of gas in a single step. This allowed us to extract the maximum amount of information from both the age spectra and the Arrhenius plots. Where applicable the age spectra were interpreted using the method of asymptotes and limits, allowing distinction of overprinting fluid systems. These new ${ }^{40} \mathrm{Ar} /{ }^{39} \mathrm{Ar}$ ages indicate that there were several distinct and separate periods of alunite growth around the Martabe deposits. This extends the known duration of acid-sulphate alteration

585 that took place at Martabe, with distinct periods of fluid activity identified that may be key to future mineral exploration.

Analysis of the Arrhenius plots put the closure temperature of alunite ranging between $400^{\circ} \mathrm{C}$ and $560^{\circ} \mathrm{C}$, which is above the temperature expected for the formation of the Martabe deposits. This result, and the heterogeneity in age, gives confidence that the measured ages from ${ }^{40} \mathrm{Ar} /{ }^{39} \mathrm{Ar}$ geochronology are

590 for the formation of alunite and that these are not cooling ages.

Although the map of the extent of the overprinting fluid systems is not complete, and lacks detail, it is evident that 'vectoring' using variation in mineral compositions to determine the direction towards the orebody could be fraught. Samples need to have been taken from the same fluid system. It is evident that mineralisation in the Purnama pit is the result of two specific fluid events, one enriching the other.

\section{Data availability}

All data is provided in the supplementary information.

\section{Author contribution}

All authors contributed to the discussion and reviewing of the manuscript. The paper includes modified information from a MPhil thesis by the first author, supervised by Prof. Gordon Lister.

\section{Disclaimer}

This article includes part of the MPhil Thesis of the first author submitted to the Research School of Earth Sciences (RSES), Australian National University.

\section{Conflicts of Interest}

The authors declare that they have no conflicts of interest. 
https://doi.org/10.5194/gchron-2021-25

Preprint. Discussion started: 13 September 2021

(c) Author(s) 2021. CC BY 4.0 License.

(c) (i)

\section{Funding Statement}

Research has been funded by the Australian Research Council Linkage Project LP130100134 "Where to find giant porphyry and epithermal gold and copper deposits" LP130100134 "Where to find giant porphyry and epithermal gold and copper deposits"].

\section{Acknowledgments}

610 Shane Paxton and Sareh Rajabi are thanked for their assistance with mineral separations.

\section{References}

Arribas, A., Arribas, I., Draper, G., Hall, C., Kesler S. E., McEwan, C., and Muntean, J.: ${ }^{40} \mathrm{Ar} /{ }^{39} \mathrm{Ar}$ dating of alunite from the Pueblo Viejo gold-silver district, Dominican Republic. Economic Geology, 106, 1059-1070, https://doi.org/10.2113/econgeo.106.6.1059, 2011.

615 Barber, A. J., and Crow, M. J.: Sumatra: geology, resources and tectonic evolution. Geological Society, London, Memoirs, 31, https://doi.org/10.1144/GSL.MEM.2005.031, 2005.

Beltrando, M., Lister, G.S., Forster, M., Dunlap, W.J., Fraser, G., Hermann, J.: Dating microstructures by the ${ }^{40} \mathrm{Ar} /{ }^{39} \mathrm{Ar}$ stepheating technique: Deformation-pressure-temperature-time history of the Penninic Units of the Western Alps. Lithos 113, 801-819, https://doi.org/10.1016/j.lithos.2009.07.006, 2009

620 Carter, J.N., Tremblay, M.M., Mark, D.F.: A Bayesian approach to the deconvolution of ${ }^{40} \mathrm{Ar} /{ }^{39} \mathrm{Ar}$ data from mineral mixtures. Chemical Geology 554, https://doi.org/10.1016/j.chemgeo.2020.119784, 2020.

Chiu, Y.-P., Yeh, M.-W., Wu, K.-H., Lee, T.-Y., Lo, C.-H., Chung, S.-L., Iizuka, Y.: Transition from extrusion to flow tectonism around the Eastern Himalaya syntaxis. GSA Bulletin 130, 1675-1696, https://doi-org /10.1130/B31811.1, 2018.

Crank, J.: The Mathematics of Diffusion: London, Ox- ford University Press, 414 pp, 1975.

625 Dodson, M. H.: Closure temperature in cooling geochronological and petrological systems. Contributions to Mineralogy and Petrology, 40, 259-274, https://doi.org/10.1007/BF00373790, 1973.

Fleck, R.J., Sutter, J.F., and Elliot, D.H.: Interpretation of discordant ${ }^{40} \mathrm{Ar} /{ }^{39} \mathrm{Ar}$ age-spectra of Mesozoic tholeiites from Antarctica: Geochimica et Cosmochimica Acta, v. 41, p. 15-32, https://doi.org/10.1016/0016- 7037(77)90184-3, 1977.

Forster, M., Koudashev, O., Nie, R., Yeung, S., and Lister, G.: ${ }^{40} \mathrm{Ar} /{ }^{39} \mathrm{Ar}$ thermochronology in the Ios basement terrane

630 resolves the tectonic significance of the South Cyclades Shear Zone. Geological Society, London, Special Publications, 487, 291-313, https://doi.org/10.1144/SP487-2018-169, 2019.

Forster, M. A., and Lister, G. S.: The interpretation of ${ }^{40} \mathrm{Ar} /{ }^{39} \mathrm{Ar}$ apparent age spectra produced by mixing: application of the method of asymptotes and limits. Journal of Structural Geology, 26, 287-305, https://doi.org/10.1016/j.jsg.2003.10.004, 2004.

635 Forster, M. A., and Lister, G. S.: Core-complex-related extension of the Aegean lithosphere initiated at the EoceneOligocene transition. Journal of Geophysical Research: Solid Earth, 114, https://doi.org/10.1029/2007JB005382, 2009.

Forster, M. A., and Lister, G. S.: Argon enters the retentive zone: reassessment of diffusion parameters for K-feldspar in the South Cyclades Shear Zone, Ios, Greece. Geological Society, London, Special Publications, 332, 17-34, https://doi.org/10.1144/SP332.2, 2010. 
https://doi.org/10.5194/gchron-2021-25

Preprint. Discussion started: 13 September 2021

(c) Author(s) 2021. CC BY 4.0 License.

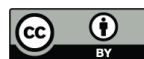

640 Forster, M.A. and Lister, G.S.: ${ }^{40} \mathrm{Ar} /{ }^{39} \mathrm{Ar}$ geochronology and the diffusion of ${ }^{39} \mathrm{Ar}$ in phengite-muscovite intergrowths during step-heating experiments in vacuo. Geological Society, London, Special Publications 378, 117-135,

https://doi.org/10.1144/sp378.16, 2014.

Forster, M.A. and Lister, G.S. and P. G. Lennox, P.G.: Dating deformation using crushed alkali feldspar: ${ }^{40} \mathrm{Ar} /{ }^{39} \mathrm{Ar}$ geochronology of shear zones in the Wyangala Batholith, NSW, Australia, Australian Journal of Earth Sciences, 61, 619-

645 629, https://doi.org/10.1080/08120099.2014.916751, 2014.

Forster, M.A., Armstrong, R., Kohn, B., Lister, G.S., Cottam, M.A., Suggate, S.: Highly retentive core domains in Kfeldspar and their implications for ${ }^{40} \mathrm{Ar} /{ }^{39} \mathrm{Ar}$ thermochronology illustrated by determining the cooling curve for the Capoas Granite, Palawan, The Philippines. Australian Journal of Earth Sciences 62, 883-902, https://doi.org/10.1080/08120099.2015.1114524, 2015.

650 Forster, M., Koudashev, O., Nie, R., Yeung, S., Lister, G.: ${ }^{40} \mathrm{Ar} /{ }^{\beta 9} \mathrm{Ar}$ thermochronology in the Ios basement terrane resolves the tectonic significance of the South Cyclades Shear Zone. Geological Society, London, Special Publications 487, 291-313, https://doi.org/10.1144/SP487-2018-169, 2020.

Ghanem, H., Kunk, M.J., Ludman, A., Bish, D.L., Wintsch, R.P.: Dating slate belts using ${ }^{40} \mathrm{Ar} /{ }^{39} \mathrm{Ar}$ geochronology and zircon ages from crosscutting plutons: A case study from east-central Maine, USA. Journal of Structural Geology 93, 51-66,

655 10.1016/j.jsg.2016.10.004, 2016.

Jourdan, F., Féraud, G., Bertrand, H., Kampunzu, A.B., Tshoso, G., Le Gall, B., Tiercelin, J.J., Capiez, P.: The Karoo triple junction questioned: evidence from Jurassic and Proterozoic ${ }^{40} \mathrm{Ar} /{ }^{39} \mathrm{Ar}$ ages and geochemistry of the giant Okavango dyke swarm (Botswana). Earth and Planetary Science Letters 222, 989-1006, 10.1016/j.eps1.2004.03.017, 2004.

Kelley, S.: Excess argon in K-Ar and Ar-Ar geochronology. Chemical Geology 188, 1-22, https://doi.org/10.1016/s00092541(02)00064-5, 2002.

Kula, J., and Spell, T.L., 2012, Recovery of muscovite age gradients by Ar-40/Ar-39 vacuum furnace step-heating analysis: Chemical Geology, 304, 166-174, https://doi.org/10.1016/j.chemgeo.2012.02.013, 2012.

Kunk, M.J., Wintsch, R.P., Naeser, C.W., Naeser, N.D., Southworth, C.S., Drake, A.A., Becker, J.L.: Contrasting tectonothermal domains and faulting in the Potomac terrane, Virginia-Maryland-discrimination by ${ }^{40} \mathrm{Ar} /{ }^{39} \mathrm{Ar}$ and fissiontrack thermochronology. Geological Society of America Bulletin 117, 1347-1366, https://doi.org/10.1130/B25599.1, 2005.

Levet, B. K., Jones, M. L., and Sutopo, B.: The Purnama gold deposit in the Martabe District of North Sumatra, Indonesia, SMEDG-AIG Symposium, 2003.

Li, J., Poureau, A., Li, Z.-X., Jourdan, F., Nordsvan, A.R., Collins, W.J., Volante, S.: Heterogeneous exhumation of the Mount Isa Orogen in NE Australia after $1.6 \mathrm{Ga}$ Nuna assembly: New high-precision ${ }^{40} \mathrm{Ar} /{ }^{39} \mathrm{Ar}$ thermochronological 670 constraints, Tectonics, 39, https://doi.org/10.1029/2020TC006129, 2020.

Love, D., H. Clark, A., J. Hodgson, C., Mortensen, J., A.: Arichibald, D. and Farrar, E.: The timing of adularia-sericite-type mineralization and alunite-kaolinite-type alteration, Mount Skukum epithermal gold deposit, Yukon Territory, Canada: ${ }^{40} \mathrm{Ar} /$ ${ }^{39} \mathrm{Ar}$ and U-Pb geochronology, 93, 437-462, https://doi.org/10.2113/gsecongeo.93.4.437, 1998.

Lovera, O. M., Grove, M., Harrison, M. T., and Mahon, K. I.: Systematic analysis of K-feldspar ${ }^{40} \mathrm{Ar} /{ }^{39} \mathrm{Ar}$ step heating 675 results: I. Significance of activation energy determinations. Geochimica et Cosmochimica Acta, 61, 3171-3192, https://doi.org/10.1016/S0016-7037(97)00147-6, 1997.

McDougall, I., and Harrison., M. T. ( $2^{\text {nd }}$ Eds.): Geochronology and thermochronology by the ${ }^{40} \mathrm{Ar} /{ }^{39} \mathrm{Ar}$ method, Oxford University Press, Oxford, UK, 1999.

Pownall, J.M., Forster, M.A., Hall, R., Watkinson, I.M., 2017. Tectonometamorphic evolution of Seram and Ambon, eastern 680 Indonesia: Insights from ${ }^{40} \mathrm{Ar} /{ }^{39} \mathrm{Ar}$ geochronology. Gondwana Research 44, 35-53, https://doi.org/10.1016/j.gr.2016.10.018, 2017. 
Ren, Z., and Vasconcelos, P. M.: Argon diffusion in hypogene and supergene alunites: Implications to geochronology and thermochronometry on Earth and Mars. Geochimica et Cosmochimica Acta, 262, 166-187, https://doi.org/10.1016/j.gca.2019.07.014, 2019.

685 Rye, R., Bethke, P., and Wasserman, M.: The stable isotope geochemistry of acid sulfate alteration. Economic Geology, 87, 225-262 https://doi.org /10.2113/gsecongeo.87.2.225, 1992.

Schaen, A.J., Jicha, B.R., Hodges, K.V., Vermeesch, P., Stelten, M.E., Mercer, C.M., Phillips, D., Rivera, T.A., Jourdan, F., Matchan, E.L., Hemming, S.R., Morgan, L.E., Kelley, S.P., Cassata, W.S., Heizler, M.T., Vasconcelos, P.M., Benowitz, J.A., Koppers, A.A.P., Mark, D.F., Niespolo, E.M., Sprain, C.J., Hames, W.E., Kuiper, K.F., Turrin, B.D., Renne, P.R.,

690 Ross, J., Nomade, S., Guillou, H., Webb, L.E., Cohen, B.A., Calvert, A.T., Joyce, N., Ganerød, M., Wijbrans, J., Ishizuka, O., He, H., Ramirez, A., Pfänder, J.A., Lopez-Martínez, M., Qiu, H., Singer, B.S., 2020. Interpreting and reporting ${ }^{40} \mathrm{Ar} /{ }^{39} \mathrm{Ar}$ geochronologic data. GSA Bulletin 133, 461-487, https://doi.org/10.1130/b35560.1, 2021.

Sharp, W.D., Renne, P.R.: The ${ }^{40} \mathrm{Ar}{ }^{39} \mathrm{Ar}$ dating of core recovered by the Hawaii Scientific Drilling Project (phase 2), Hilo, Hawaii. Geochemistry, Geophysics, Geosystems 6, n/a-n/a. https://doi.org/10.1029/2004GC000846, 2005.

695 Spell, T. L., and McDougall, I.: Characterization and calibration of ${ }^{40} \mathrm{Ar} /{ }^{39} \mathrm{Ar}$ dating standards. Chemical Geology, 198, 189211, 2003.

Steiger, R. H., and Jager, E.: Subcommission on geochronology: Convention on the use of decay constants in geo- and cosmochronology. Earth and Planetary Science Letters, 36, 359-362, https://doi.org/10.1016/0012-821X(77)90060-7, 1977.

Stenhouse, I.R., Forster, M.A., Lister, G.S.: The timing of sedimentation and Buchan metamorphism in the Grampian

700 Terrane in Scotland from ${ }^{40} \mathrm{Ar} /{ }^{39} \mathrm{Ar}$ apparent age spectra. Journal of the Geological Society 171, 343-352. https://doi.org/10.1144/jgs2013-078, 2014.

Sutopo, B.: The Martabe Au-Ag high-sulfidation epithermal deposits, Sumatra, Indonesia: implications for ore genesis and exploration, Ph.D. thesis, University of Tasmania, Australia, 2013.

Viete, D.R., Oliver, G.J.H., Fraser, G.L., Forster, M.A., Lister, G.S.:. Timing and heat sources for the Barrovian metamorphism, Scotland. Lithos 177, 148-163., https://doi.org/10.1016/j.lithos.2013.06.009, 2013.

White, N. C., and Hedenquist, J. W.: Epithermal environments and styles of mineralization: Variations and their causes, and guidelines for exploration. Journal of Geochemical Exploration, 36, 445-474, https://doi.org/10.1016/0375-6742(90)90063G, 1990. 